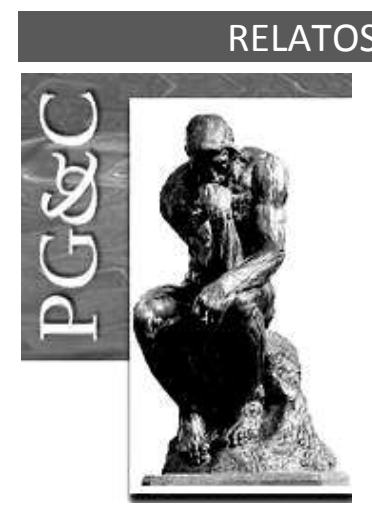

\title{
ANÁLISE DAS REDES DE COAUTORIA SOBRE FLUXOS DE INFORMAÇÃO NA BASE DE DADOS BRAPCI
}

\author{
Alzira Karla Araújo da Silva \\ Doutora em Ciência da Informação pela Universidade Federal de Minas \\ Gerais, Brasil. Professora da Universidade Federal da Paraíba, Brasil. \\ E-mail: alzirakarlaufpb@gmail.com \\ Bárbara Carvalho Diniz \\ Mestranda em Ciência da Informação pela Universidade Federal da \\ Paraíba, Brasil. \\ E-mail: dinizbarbara6@gmail.com \\ Flávia de Araújo Telmo \\ Doutoranda em Ciência da Informação pela Universidade Federal da \\ Paraíba, Brasil. \\ E-mail: flaviaaraujo.t@gmail.com \\ Natanael Vitor Sobral \\ Doutor em Ciência da Informação pela Universidade Federal da Bahia, \\ Brasil. Professor da Universidade Federal da Bahia, Brasil. \\ E-mail: natanvsobral@gmail.com \\ Elaine Cristina de Brito Moreira \\ Mestra em Gestão nas Organizações Aprendentes pela Universidade \\ Federal da Paraíba, Brasil. Bibliotecária da Sociedade de Ensino Superior \\ da Paraíba, Brasil. \\ E-mail: elainemoreir@gmail.com
}

\begin{abstract}
Resumo
Analisa as redes de coautoria sobre fluxos de informação em artigos de periódicos indexados pela Base de Dados Referencial de Artigos de Periódicos em Ciência da Informação (Brapci), no período de 2000 a 2019. A pesquisa caracteriza-se como descritiva e quantitativa, com aplicação da análise de redes sociais. A representação visual dos resultados foi realizada com o uso das ferramentas Ucinet e NetDraw, pautando-se em dados bibliográficos organizados no Microsoft Excel. Identifica que a rede sobre fluxos de informação na Brapci é formada por 86 atores pertencentes a 23 instituições, com 46 artigos indexados em 19 periódicos. Perspectivas em Gestão \& Conhecimento da UFPB foi o periódico com maior destaque. Nota-se o crescimento do número de artigos sobre o tema a partir de 2012. Ressalta os atores RADOS, G. J. V. e VALENTIM, M. L. P., como fundamentais na rede e com o maior número de publicações. Revela que a Universidade Federal de Santa Catarina (UFSC) destaca-se entre as instituições com maior número de artigos indexados na Brapci sobre o tema, seguida da Universidade Estadual Paulista (UNESP). Dentre os 37 temas associados a fluxos de informação, sobressaíram-se: processos de tomada de decisão e gestão documental. Por fim, constata-se a existência de um corpus significativo de estudos sobre fluxos de informação, constituído por um conjunto de pesquisas que visam potencializar o uso e a circulação da informação em diversos contextos.
\end{abstract}

Palavras-chave: Fluxos de informação. Análise de redes. Redes de coautoria. Brapci. 


\title{
ANALYSIS OF CO-AUTHORING NETWORKS ON INFORMATION FLOWS IN THE BRAPCI DATABASE
}

\begin{abstract}
It analyzes the co-authoring networks on information flows in journal articles indexed by the Reference Database of Information Science Journals (Brapci), from 2000 to 2019. The research is characterized as descriptive and quantitative, with application of social network analysis. The visual representation of the results was performed using the Ucinet and NetDraw tools, based on bibliographic data organized in Microsoft Excel. It identifies that Brapci's network on information flows is made up of 86 actors from 23 institutions, with 46 articles indexed in 19 journals. Perspectivas em Gestão \& Conhecimento from UFPB was the most prominent journal. There is a growing number of articles on the topic since 2012. Highlights the actors RADOS, G. J. V. and VALENTIM, M. L. P. as fundamentals in the network the with largest number of publications. It reveals that the Universidade Federal de Santa Catarina (UFSC) stands out among the institutions with the largest number of articles indexed in Brapci on the subject, followed by the Universidade Estadual Paulista (UNESP). Among the 37 themes associated with information flows, the following stood out: decision-making processes and document management. Finally, there is a significant corpus of studies on information flows, consisting of a set of researches aimed at enhancing the use and circulation of information in various contexts.
\end{abstract}

Keywords: Information flows. Network analysis. Co-authoring networks. Brapci.

\section{INTRODUÇÃO}

Na Ciência da Informação $(\mathrm{Cl})$, os termos "fluxo informacional" ou "fluxos de informação" expressam uma sucessão de acontecimentos exercidos de maneira dinâmica, que culminam no encadeamento, criação ou a inconstância de ocorrências associadas às práticas informacionais (BARRETO, 2005).

Os fluxos de informação passam por uma sequência de acontecimentos, podendo abranger os cenários interno e externo de uma organização; indo desde a identificação da necessidade da informação, passando pela sua obtenção, tratamento, armazenamento, distribuição, uso, até o seu descarte (BEAL, 2004).

Valentim (2010) afirma que o ambiente organizacional é um grande influenciador na existência dos fluxos de informação, sendo responsável pelo seu surgimento e permanência. Para que os fluxos sejam criados, mantidos e gerenciados de forma adequada é necessário que a cultura e a comunicação da organização propiciem sua "alimentação", pois, recebem influência direta e indireta da cultura organizacional em que são produzidos (FERNANDES, 2013).

Os fluxos de informação têm sido estudados, pois é necessário compreender como as informações são coletadas, repassadas e mantidas dentro e fora das organizações para seu potencial uso, seja por meio de sistemas, processos e/ou pessoas.

Sendo assim, esta pesquisa justifica-se pela relevância dos estudos sobre fluxos de informação nos processos infocomunicacionais existentes em grupos sociais, neste caso, o da comunidade científica, que tem na informação seu principal fator de interação, sendo importante a compreensão da estrutura social científica desses pesquisadores para a análise da interatividade empregada no desenvolvimento científico e nas possibilidades de ampliação de parcerias e abordagens colaborativas.

Silva, Câmara e Barros (2017) ressaltam a importância de compreender como ocorre o crescimento e a institucionalização das disciplinas do saber como uma necessidade constante. Acrescentam que o crescimento e o progresso dos estudos e pesquisas científicas são potencializados à medida que são divulgados para a comunidade. Na maioria das vezes, isso é

Perspectivas em Gestão \& Conhecimento, João Pessoa, v. 10, número especial, p. 136-159, mar. 2020. 
possível por meio da colaboração entre os pesquisadores, atuando de modo cooperativo, em rede, devido ao engajamento proporcionado por seus interesses comuns.

A análise de redes sociais (ARS) oferece subsídios para a interpretação da sociedade como um conjunto de indivíduos, organizações e instituições, vinculados uns aos outros, constituindo redes de relacionamento, com uma dinâmica interacional baseada em características distintas e específicas de cada grupo, sendo estes comportamentos passíveis de análise, a exemplo das parcerias na produção técnico-científica, que se materializam nos artigos científicos e demais publicações de natureza técnica ou bibliográfica.

A partir desse aporte teórico-metodológico, que observa a sociedade, seus atores e atributos a partir dos vínculos estabelecidos entre os sujeitos, é possível perceber as idiossincrasias entre grupos de indivíduos, que podem ser observadas a partir de dinâmicas de centralidade, vizinhança, proximidade, influência, isolamento e outras variáveis comportamentais. No âmbito da comunicação científica, o arcabouço desenvolvido no interior do domínio da ARS por seus agentes serve de contributo para a investigação do relacionamento entre instituições, pesquisadores, organizações e documentos (RUAS; FERREIRA; 2016). "As redes sociais e a análise dessas relações vêm, portanto, medir a colaboração científica entre pesquisadores, instituições e países para visualizar o estado da arte da pesquisa em determinada área do conhecimento." (SILVA, 2015, p. 45).

Em geral, essas redes são representadas por meio da proposição de um modelo denominado "sociograma", que se apresenta como um esquema de representação das propriedades formais das configurações sociais. Essas se configuram em diagramas nos quais os indivíduos são representados por "pontos" e suas relações sociais por "linhas" (BRAGA; GOMES; RUEDIGER, 2008).

Para a visualização dessas estruturas no contexto científico, um dos principais aspectos analisados é a coautoria, a partir das publicações científicas, seja em bases de dados, de informações ou de documentos científicos, com identificação de autores e seus vínculos, relacionando-se com suas produções, temas abordados, entre outras variáveis.

As bases científicas são recursos eletrônicos que reúnem publicações validadas, em geral, avaliadas por pares. As bases de dados científicos concentram-se em metadados sobre as publicações e são importantes para a obtenção de dados sobre autoria, assunto, ano, título, fonte etc.; as bases de informação científica carregam painéis de indicadores capazes de representar conjuntos de informações mais sofisticadas, valendo-se de conjuntos de dados organizados para inferir sobre tendências da produção científica, autores mais produtivos, avanços e retrocessos nas publicações; já as bases de documentos científicos lidam, propriamente, com o armazenamento de documentos, oferecendo opções de recuperação de textos e outras tipologias documentais.

Comumente, tem-se observado um processo de convergência nesses modos de oferta de conhecimento científico, e por isso, algumas bases vão além da disponibilização de documentos, fundamental para leitores e estudiosos; possibilitando o acesso a dados e informações organizados, importantes para a realização de pesquisas no domínio métrico da informação, pautando-se em artigos de periódicos, livros, trabalhos publicados em anais de evento etc.

Existem bases que abrangem diversos tipos de conhecimento científico, porém, outras se direcionam a determinada(s) área(s) do saber. Este é o caso da Base de Dados Referencial de Artigos de Periódicos em Ciência da Informação (Brapci), que indexa produções científicas desde 1972 no campo da $\mathrm{Cl}$ no Brasil, justificando sua utilização. Ademais, a Brapci reúne metadados sobre quase 20.000 publicações, estando em constante atualização, o que denota a relevância dessa fonte para estudos de produção científica em âmbito nacional, sendo mais que uma base de dados, por reunir dados, informações e documentos.

Perspectivas em Gestão \& Conhecimento, João Pessoa, v. 10, número especial, p. 136-159, mar. 2020. 
Assim, este artigo tem como objetivo geral analisar as redes de coautoria dos artigos indexados em periódicos sobre o tema "fluxos de informação" na base Brapci entre os anos 2000 a 2019. Para isso, buscou identificar os atores que publicaram artigos em periódicos indexados na Brapci sobre o tema proposto; mapear as relações de coautoria entre os atores dessa rede; identificar o vínculo institucional destes atores; apresentar a estrutura em rede que esses atores constituem e; obter um panorama das publicações sobre fluxos de informação.

O artigo está organizado a partir da introdução, na qual explicitam-se de maneira sucinta o tema abordado e os objetivos do estudo. A segunda seção procura revisar teoricamente o tema "fluxos de informação". A terceira descreve a metodologia e os procedimentos de coleta e análise utilizados. A quarta seção apresenta os resultados da rede de coautoria pesquisada. E por fim, têm-se as considerações finais, as referências e um apêndice com os resultados gerais dos artigos sobre fluxos de informação indexados na Brapci (2000 a 2019).

\section{FLUXOS DE INFORMAÇÃO}

Fluxos não só representam um elemento da organização social, mas constituem expressões dos processos que dominam a vida econômica, política e simbólica de todos. Fluxos de informação, por sua vez, são sequências intencionais, repetitivas e programáveis que intercambiam e interagem entre posições fisicamente desarticuladas, mantidas pelos atores sociais nas estruturas econômica, política e simbólica da sociedade (CASTELLS, 2001).

Os fluxos de informação têm ligação direta com a Gestão da Informação (GI), visto que esta lida com processos de obtenção, tratamento, armazenamento, organização, distribuição, disseminação e uso das informações no contexto organizacional. Assim, constituem um processo de informação complexo e contínuo que perpassa as etapas da GI.

Existem, então, elementos que compõem os fluxos de informação e aspectos que influenciam diretamente este processo, como por exemplo, as barreiras informacionais para acesso e uso da informação. Conhecer então os ruídos que causam interferência no compartilhamento de informações é fundamental, já que dessa maneira identificam-se problemas, possibilitando ações para que a informação circule da melhor forma (INOMATA et al., 2017), pois,

Os fluxos informacionais ocorrem em todos os momentos em que há a comunicação e o compartilhamento de informação, e são essenciais para qualquer ambiente informacional. No contexto organizacional além de estarem presentes, se faz indispensável mapeá-los e compreendê-los, pois o que possibilita à organização a obtenção de vantagem competitiva frente à concorrência consiste no diferencial dado ao tratamento e uso das informações e do conhecimento (SANTARÉM; VITORIANO, 2016, p. 165).

Nas organizações existem diversos recursos tangíveis, a exemplo das máquinas, materiais e o capital. Contudo, existem os recursos intangíveis, como a informação e o conhecimento. A organização se torna mais competitiva quando utiliza e aproveita os recursos tangíveis e intangíveis. Os fluxos de informação, uma vez sendo identificados e gerenciados, podem auxiliar o profissional da informação no contexto organizacional no que concerne ao mapeamento do caminho que as informações percorrem, bem como, na análise de falhas ou erros durante o percurso (SANTARÉM; VITORIANO, 2016). Esse processo pode ser entendido da seguinte forma:

Perspectivas em Gestão \& Conhecimento, João Pessoa, v. 10, número especial, p. 136-159, mar. 2020. 
[...] o fluxo da informação opera em um sistema de criação da informação que, através de um sistema de processamento, recuperação e uso, possibilitará sua apropriação pelo usuário (receptor) que poderá consolidála em conhecimento através de um processo de transformação de uma situação preexistente (SAVI; SILVA, 2009, p. 181).

Percebe-se que os fluxos de informação perpassam por um sistema em seus processos de coleta, recuperação e uso e o(s) receptor(es) da informação faz(em) uso deste elemento. Fernandes e Garcia (2013) relatam que a gestão dos fluxos de informação é um componente essencial para as organizações, uma vez que, por meio dos fluxos circulam as informações produzidas, distribuídas e utilizadas pelos três níveis organizacionais: estratégico, tático e operacional.

Uma das suas principais funções dos fluxos de informação é conceber aos gestores subsídios necessários aos processos de tomada de decisão. As organizações que administram eficientemente suas informações dispõem de um recurso estratégico essencial para maximizar a qualidade de seus processos decisórios. Investigar os fluxos informacionais permite a verificação e subsídio dos processos de tomada de decisão. Mapeando os fluxos é possível reconhecer as etapas pelas quais a informação circula e identificar quais aspectos são falhos no processo. É então necessário conhecer as necessidades de uso e usuários da informação para mapear as fontes de informação adequadas ao contexto (VITAL; FLORIANI; VARVAKIS, 2010).

Destacam-se dois tipos de fluxos de informação: os formais (estruturados) e os informais (não estruturados), descritos a seguir:

Os fluxos estruturados consistem em informações que de alguma maneira estão registradas em algum tipo de suporte, por outro lado os fluxos não estruturados se constituem em informações não registradas, mas nem por isso deixam de ser informação. Os fluxos informais ou não estruturados fazem parte dos recursos não tangíveis que uma organização possui. No entanto, possuem grande relevância para a organização, e abrangem o conhecimento gerado no ambiente organizacional e, que muitas vezes, não foram percebidos e sistematizados. Este tipo de conhecimento quando sistematizado e trabalhado pode auxiliar a organização em distintos e significativos momentos. Os fluxos formais ou estruturados são constituídos de informações, ou seja, fazem parte dos recursos tangíveis que a organização possui. [...] (NASCIMENTO; VALENTIM; CABERO, 2017, p. 65).

Tendo em vista que estes fluxos se referem à informação que percorre o espaço e o sistema organizacional nas etapas de coleta, obtenção, difusão e uso da informação, para então chegar aos seus receptores, entende-se que a gestão desses fluxos é primordial, sobretudo, para que a organização atue de modo estratégico, potencializando seus processos de tomada de decisão.

Starec (2002) ressalta quatro fatores que impedem o livre fluxo da informação, conforme demonstrado no Quadro 1:

Quadro 1 - Barreiras que impedem o livre fluxo da informação

\begin{tabular}{|c|l|}
\hline Barreira & \multicolumn{1}{|c|}{ Descrição } \\
\hline $\begin{array}{c}\text { Má } \\
\text { comunicação }\end{array}$ & $\begin{array}{l}\text { De acordo com pesquisas americanas, a má comunicação é o segundo item que } \\
\text { mais prejudica a qualidade das empresas. Neste caso a comunicação seria um } \\
\text { processo que possui começo, meio, mas não tem fim. }\end{array}$ \\
\hline $\begin{array}{c}\text { Cultura } \\
\text { organizacional }\end{array}$ & $\begin{array}{l}\text { O conhecimento estratégico proporciona um comportamento estratégico, este } \\
\text { passa a integrar a cultura organizacional da instituição, levando ao comportamento }\end{array}$ \\
\hline
\end{tabular}

Perspectivas em Gestão \& Conhecimento, João Pessoa, v. 10, número especial, p. 136-159, mar. 2020. 


\begin{tabular}{|c|l|}
\hline \multirow{5}{*}{$\begin{array}{c}\text { Falta de } \\
\text { Competência }\end{array}$} & $\begin{array}{l}\text { competitivo. Se a cultura da organização não promove o fluxo informacional que } \\
\text { Ihe é proposto, as informações pertinentes não serão recuperadas. } \\
\text { esta barreira requer cuidados especiais, pois é a mais delicada. As pessoas são } \\
\text { diminuem-se as pásico de qualquer instituição. Não existem empresas, instituições, } \\
\text { estratégico da informação. Esta barreira pode ocorrer por falhas nos processos de } \\
\text { comunicação, bem como se a cultura organizacional não valoriza o seu pessoal. }\end{array}$ \\
\hline \multirow{5}{*}{ Tecnológica } & $\begin{array}{l}\text { As tecnologias da informação e comunicação desempenham o papel de colaborar } \\
\text { com a vida dos seres humanos e das organizações, no entanto, nem sempre trazem } \\
\text { os benefícios esperados. O valor da tecnologia da informação depende, acima de } \\
\text { tudo, da informação e do papel desta desempenhada na organização. Investir } \\
\text { apenas nas tecnologias da informação e comunicação não basta, em primeiro lugar } \\
\text { deve ser dado prioridade a uma administração informacional centrada nos seres } \\
\text { humanos. }\end{array}$ \\
\hline
\end{tabular}

Fonte: Adaptado de Starec (2002)

As barreiras supracitadas podem prejudicar, bem como comprometer a circulação da informação. Por esta razão, gerenciar informações e seus fluxos é decisivo para as organizações que desejam utilizar a informação e o conhecimento como recursos estratégicos. Caso existam barreiras nesse fluxo, compete aos gestores identificar os problemas e propiciar a livre circulação da informação.

Uma estratégia considerável para o gerenciamento dos fluxos de informação é a preservação da memória organizacional, por ser gerada por meio do conhecimento coletivo. Para Nascimento et al. (2016), preservar a memória organizacional, além de gerar aprendizagem para os sujeitos da organização, se torna um diferencial competitivo em detrimento da importância que eles atribuem a informação e ao conhecimento, auxiliando no processo decisório para tomada de decisão. Diante desta perspectiva, percebe-se que a memória organizacional auxilia nas ações futuras da organização e preserva a sua história, transparecendo a sua evolução ao longo do tempo.

Nascimento et al. (2016) ainda ressaltam a importância de um sistema sustentável que possa controlar a informação de forma eficiente, eficaz e sistemática, possibilitando sua geração, recepção, uso, manutenção, conservação e disseminação, facilitando o gerenciamento dos processos e fluxos da informação.

Partindo das premissas abordadas neste artigo, e pensando em inovação, percebe-se que os fluxos de informação estão em constante evolução e tornam-se necessários nas organizações e na vida dos sujeitos organizacionais, que devem estar envolvidos nos processos gerenciais para que o compartilhamento de informação possa ocorrer de maneira eficaz e eficiente.

Agregar fluxos de informação às tecnologias é um fator importante para o desenvolvimento e crescimento da organização, o que vai gerar cada vez mais conhecimento na sociedade. Inovar gera competitividade, que, por sua vez, gera informação e a informação gera conhecimento, fomentando um ciclo no qual a inovação se transforma em aprendizado, gerando uma rede social de colaboração.

Corroborando com Araújo (2017, p. 60),

[...] o fluxo de informação está inserido, como fator crucial, nos processos de inovação. Inovar tem se tornado o objetivo da maioria das organizações tendo em vista o contexto econômico competitivo, dinâmico e turbulento que obriga as organizações a se renovar e inserir novos bens e serviços para atender às necessidades de sua rede de clientes.

Perspectivas em Gestão \& Conhecimento, João Pessoa, v. 10, número especial, p. 136-159, mar. 2020. 
Diante desta perspectiva, se pode pensar que inovar também requer a busca das melhores práticas no ambiente organizacional a fim de transformá-las. Desta forma, "as redes sociais vêm se configurando como ferramenta de importante observação na análise dos fluxos de informação" (INOMATA; RADOS, 2015, p. 5), ou seja, a partir do conhecimento individual do ator, o compartilhamento de informação contribui para o surgimento de novas ações, interligando as pesquisas e favorecendo a aprendizagem contínua.

\section{METODOLOGIA}

Do ponto de vista de seus objetivos, esta pesquisa se classifica como descritiva, pois descreve as características de determinados fenômenos, ocorrências, ou estabelecimento das relações de uma população, sem a interferência do pesquisador nos acontecimentos, que os observa e registra (GIL, 2010). De fato, a pesquisa em questão descreve os fatos observados, a partir da abordagem de ARS com representação gráfica de coautoria na produção científica sobre "fluxos de informação" na base Brapci, que tem em sua coleção 68 periódicos nacionais relacionados à $\mathrm{Cl}$, datados de 1972 até o momento atual. Também indexa alguns periódicos internacionais, artigos de conferências e encontros da área, resumos de artigos, teses e dissertações.

A Brapci possui mecanismos de busca "simples" e "avançado". Na Figura 1, é possível observá-los.

Figura 1- Tela de busca da Brapci

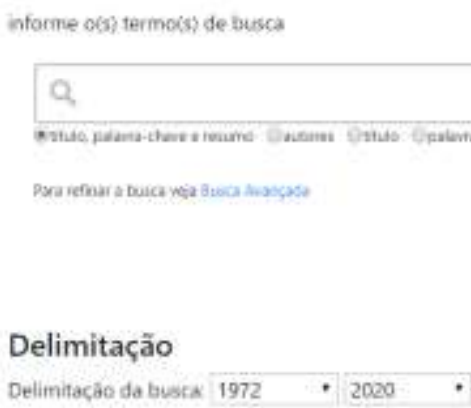

Fonte: Brapci (2020)

$\mathrm{Na}$ caixa de pesquisa insere(m)-se o(s) termo(s) e a base busca as correspondências sintáticas pertinentes. É possível, também, recuperar informações a partir do(s) nome(s) do(s) autor(es), título do artigo ou periódico, palavras-chave, resumo ou referências. É possível delimitar a busca por determinado ano ou período. Em relação à busca avançada, a Brapci usa mecanismos de refinamento, conforme o Quadro 2:

Quadro 2 - Mecanismos de busca avançados utilizados pela Brapci

\begin{tabular}{|l|l|}
\hline \multicolumn{1}{|c|}{ FORMA DE BUSCA } & \multicolumn{1}{c|}{ EXEMPLO } \\
\hline Termo composto & Nome do termo entre “aspas”. Ex: "fluxo de informação” \\
\hline Variação de termos & Nome do termo com asterisco*. Ex: *fluxos de informação* \\
\hline Pela variação de uma letra dos termos & Nome do termo com interrogação. Ex: indexad?r \\
\hline Pela variação do termo & $\begin{array}{l}\text { Termos com início e fim. nome do termo com asteriscos, } \\
\text { ex:Bib*ca. Irá retornar tudo que comece com BIB e termine } \\
\text { com CA }\end{array}$ \\
\hline
\end{tabular}

Perspectivas em Gestão \& Conhecimento, João Pessoa, v. 10, número especial, p. 136-159, mar. 2020. 


\begin{tabular}{|l|l|}
\hline Busca composta & $\begin{array}{l}\text { Insere automaticamente o termo OR (ou) entre os termos. Ex: } \\
\text { Bibliometria OR citação }\end{array}$ \\
\hline Ocorrência de termos & $\begin{array}{l}\text { Inclusão do termo AND (E) entre os termos. Ex: Gestão AND } \\
\text { arquivos }\end{array}$ \\
\hline $\begin{array}{l}\text { Busca com mais de um termo com } \\
\text { atribuição de peso maior a determinado } \\
\text { termo }\end{array}$ & $\begin{array}{l}\text { Atribuir a indicação “^” e o peso atribuído. Ex: Biblioteca AND } \\
\text { Universitária^10. }\end{array}$ \\
\hline
\end{tabular}

Fonte: Adaptado da Brapci (2020)

Para encontrar os artigos sobre o tema proposto, foram utilizados os termos "fluxos informacionais" e "fluxos de informação" (foram utilizadas aspas, pois os termos são compostos, facilitando a precisão da busca). Foram encontrados 98 resultados com o termo "fluxos informacionais" e 79 com "fluxos de informação", no período de 2000 a 2019.

Foram excluídos trabalhos e resumos de conferências, encontros, resumos de teses e dissertações, já que a pesquisa focou em artigos de periódicos. Foram analisados os resumos e as palavras-chave dos artigos pré-selecionados, chegando então ao número de 46 resultados que tratavam sobre o tema fluxos de informação/fluxos informacionais.

A análise visual dos resultados foi obtida por meio da inserção dos dados em planilha elaborada no software Microsoft Excel ${ }^{\circledast}$ e construção de tabelas e quadros; assim como, matrizes e grafos com o uso dos softwares Ucinet e NetDraw para representar a rede social de coautoria sobre fluxos de informação de artigos indexados na Brapci.

\footnotetext{
Um ponto importante ao se estudar a análise de redes sociais diz respeito a seus aspectos qualitativo e quantitativo. Os métodos e técnicas de análise de redes sociais nos levam, em um primeiro momento, a colocá-la como um método quantitativo em virtude de sua abordagem: ao utilizar a base matemática e estatística para demonstrar as redes, permite a sistematização da informação de forma a possibilitar a visualização da sua estrutura e de seus padrões, o que a torna mais quantitativa. (SOUZA, 2007, p.124).
}

Na dinâmica metodológica da ARS, a rede é representada em estruturas de grafos e cada ator é representado por um nó, sendo cada aresta correspondente as suas ligações (GONZALEZ AGUILAR et al., 2017, p. 191). Sendo assim, a compreensão de conceitos elementares torna-se fundamental como o de grafo que é uma "[...] representação apoiada em modelos matemáticos, utilizada pela metodologia de ARS, que permite visualizar um conjunto de nós, um (ou mais), conjunto(s) de linhas entre pares e nós." (LARA; LIMA, 2009, p. 622).

O conceito de nó (vértice/ponto) representa cada "ator de uma rede social" (LARA; LIMA, 2009, p. 625). As arestas são uma "relação não orientada entre dois atores" (LEMIEUX; OUITMET, 2004, p. 117) e os vínculos (ligações/laços/arcos) entre atores "constituem canais para transferência ou fluxo de recursos materiais e não materiais." (LARA; LIMA, 2009, p. 624).

Diante do exposto, foram identificados os atores e a instituições que se encontravam vinculados, a quantidade de artigos que cada ator produziu, as relações de coautoria, a intensidade das relações, em quais periódicos os artigos foram publicados e, por fim, a quantidade de artigos publicados em cada ano do período analisado. Por relações entende-se "[...] um conjunto de laços que respeitam o mesmo critério de relacionamento dado um conjunto de atores em uma rede social." (LARA; LIMA, 2009, p. 634) e por intensidade entende-se a "variedade de relações que se tramam nas teias armadas entre pesquisadores

Perspectivas em Gestão \& Conhecimento, João Pessoa, v. 10, número especial, p. 136-159, mar. 2020. 
dentro do grupo de pesquisa sob a liderança de um ou mais pesquisadores." (CAREGNATO, et al., 2014).

Na ARS, a principal característica a ser analisada são as propriedades relacionais, identificadas pela interação existente entre no mínimo dois atores, mantendo ligações, sejam elas de força forte (maior frequência) ou ligações com força fraca (menor frequência) (HAYTHORNTHWAITE, 2015).

\section{FLUXOS DE INFORMAÇÃO NA BRAPCI: RESULTADOS DA PESQUISA}

Esta seção se dedica a apresentar os resultados da análise das redes de coautoria em artigos de periódicos indexados pela Brapci sobre o tema fluxos de informação, no intervalo de tempo entre 2000 a 2019, totalizando 19 anos de produção científica.

O Grafo 1 representa a rede social de coautoria dos atores com artigos sobre o tema "fluxos de Informação" indexados na Brapci de 2000 a 2019.

Grafo 1 - Rede Social de coautoria dos atores com artigos sobre o tema "fluxos de informação" indexados na Brapci (2000 a 2019)

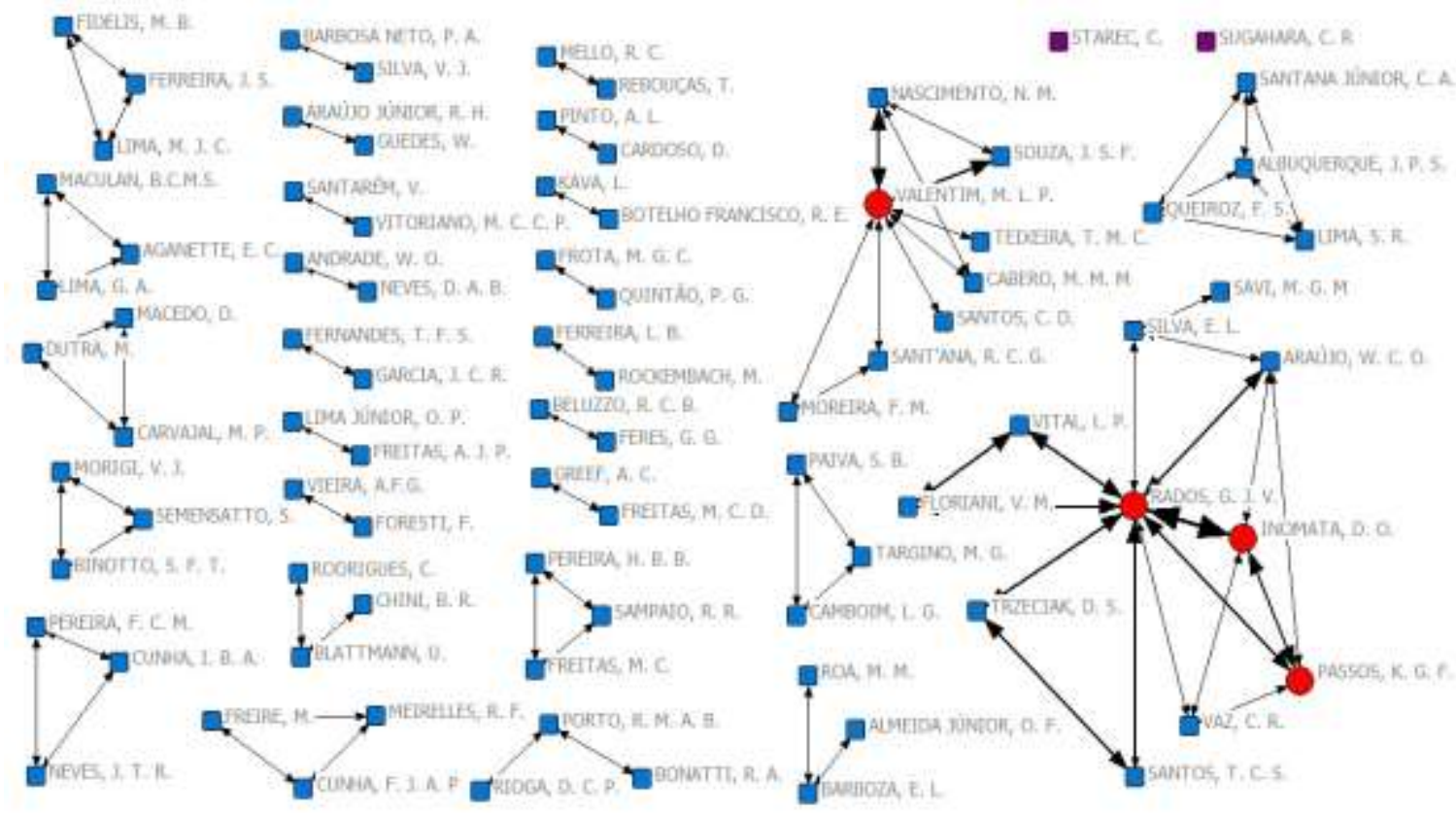

Fonte: Dados da Pesquisa (2020)

Identificaram-se na rede social 30 sub-redes, compostas por 86 atores, oriundas da produção de 46 artigos sobre o referido tema, sendo a maioria das relações estabelecidas por díades (dois atores) e tríades (três atores). Sendo, 14 subgrafos constituídos por relações díades e 11 por relações tríades.

Verificou-se na rede dois atores STAREC, C. e SUGAHARA, C. R., que não produziram em colaboração com outros atores e sim de modo individual.

Destacaram-se como atores dominantes, no grafo da interação social analisado, os atores: RADOS, G. J. V. (16 relações com nove atores), VALENTIM, M. L. P. (nove relações com sete atores), INOMATA, D. O. (sete relações com quatro atores) e PASSOS, K. G. F. (seis relações com quatro atores). Esses sujeitos mostraram-se fundamentais para manutenção dessa estrutura social, ou seja, destacam-se na produção científica sobre fluxos informacionais e mantém a comunicação entre os pesquisadores, seja por processos formais ou informais.

Perspectivas em Gestão \& Conhecimento, João Pessoa, v. 10, número especial, p. 136-159, mar. 2020. 
Com isso, perceberam-se quatro atores centrais na rede, permitindo inferir sobre a importância desses sujeitos para o avanço da colaboração e o desenvolvimento de estudos sobre o assunto em foco nesse artigo, em especial, a partir de estratégias de interação interinstitucional e o desenvolvimento habilidades relacionais com indivíduos distintos, proporcionando a agregação da rede.

\begin{abstract}
A rede social merece a adjetivação de Colaborativa ou Cooperativa quando todos que a integram, não apenas os que são nós ou membros integradores contribuem significativamente para o grupo, se empenham em disseminar via rede o que for de interesse comum, partilham as informações com todos. Nesse tipo de rede social todos colaboram para melhorar o desempenho de cada um ou o produto que estejam elaborando, ou atingir os objetivos gerais ou os específicos estabelecidos. (WITTER, 2009, p. 171).
\end{abstract}

Evidenciaram-se duas sub-redes mais representativas, sendo mais denso o subgrafo com interação entre 11 atores e a sub-rede com interação com oito atores.

A rede apresentou coesão social (laços fortes) nas relações do ator VALENTIM, M. L. P. com NASCIMENTO, N. M. (duas ligações), outro vínculo relacional de VALENTIM, M. L. P. com SOUZA, J. S. F. (duas ligações), e VALENTIM, M. L. P., com CABERO, M. M. M (duas ligações).

Constatou-se também coesão social no subgrafo que tem como centralidade RADOS, G. J. V., sendo: três relações de RADOS, G. J. V com o ator INOMATA, D. O., e duas relações de RADOS, G. J. V. com cada um dos atores: ARAÚJO, W. C. O.; PASSOS, K. G. F.; SANTOS. T. C. S.; TRZECIAK, D. S.; e FLORIANI, V. M; VITAL, L. P.

Também, colaboraram no mesmo subgrupo os atores: VITAL, L. P. e FLORIANI, V. M. (duas relações); INOMATA, D. O. e PASSOS, K. G. F. (duas relações) e SANTOS, T. C. S. e TRZECIAK, D. S. (duas relações). Os demais coautores que apresentaram apenas uma ocorrência relacional são descritas em nota de rodapé . $^{2}$

Em seguida, apresenta-se a quantidade de artigos recuperados na Brapci, com abordagem sobre fluxos de informação, relacionando-os com a autoria.

Tabela 1 - Quantidade de artigos sobre fluxos de informação por autores indexados na Brapci (2000 a 2019)

\begin{tabular}{c|l}
\hline $\begin{array}{c}\text { QUANTIDADE } \\
\text { DE ARTIGOS }\end{array}$ & \multicolumn{1}{c}{ ATORES } \\
\hline 8 & RADOS, G. J. V. \\
\hline 6 & VALENTIM, M. L. P. \\
\hline 3 & INOMATA, D. O. \\
\hline \multirow{2}{*}{2} & TRZECIAK, D. S.; SILVA, E. L.; BARBOZA, E. L.; SOUZA, J. S. F.; PASSOS, K. G. F.; VITAL, \\
& $\begin{array}{l}\text { L. P.; CABERO, M. M. M; NASCIMENTO, N. M.; PORTO, R. M. A. B.; SANTOS, T. C. S.; } \\
\text { BLATTMANN, U.; FLORIANI, V. M. e ARAÚJO, W. C. O. }\end{array}$ \\
\hline \multirow{2}{*}{1} & $\begin{array}{l}\text { PINTO, A. L.; FREITAS, A. J. P.; GREEF, A. C.; VIEIRA, A.F.G.; MACULAN, B.C.M.S.; } \\
\text { CHINI, B. R.; VAZ, C. R.; SANTOS, C. D.; SANTANA JÚNIOR, C. A.; RODRIGUES, C.; } \\
\text { SUGAHARA, C. R; STAREC, C.; CARDOSO, D.; RIOGA, D. C. P.; MACEDO, D.; NEVES, D. }\end{array}$ \\
\hline
\end{tabular}

${ }^{1}$ PINTO, A. L.; FREITAS, A. J. P.; GREEF, A. C.; VIEIRA, A. F. G.; CHINI, B. R.; SANTOS, C. D.; RODRIGUES, C.; CARDOSO, D.; RIOGA, D. C. P.; NEVES, D. A. B.; FORESTI, F.; FERES, G. G.; GARCIA, J. C. R.; FERREIRA, L. B.; KAVA, L.; VITORIANO, M. C. C. P.; FREITAS, M. C. D.; SAVI, M. G. M; FROTA, M. G. C.; ROA, M. M.; ROCKEMBACH, M.; LIMA JÚNIOR, O. P.; ALMEIDA JÚNIOR, O. F.; QUINTÃO, P. G.; BARBOSA NETO, P. A.; BELUZZO, R. C. B.; MELLO, R. C.; BOTELHO FRANCISCO, R. E.; BONATTI, R. A.; ARAÚJO JÚNIOR, R. H.; REBOUÇAS, T.; FERNANDES, T. F. S.; TEIXEIRA, T. M. C.; SILVA, V. J.; SANTARÉM, V.; ANDRADE, W. O. e GUEDES, W.

Perspectivas em Gestão \& Conhecimento, João Pessoa, v. 10, número especial, p. 136-159, mar. 2020. 
A. B.; AGANETTE, E. C.; MOREIRA, F. M.; QUEIROZ, F. S.; FORESTI, F.; PEREIRA, F. C. M.; LIMA, G. A.; FERES, G. G.; PEREIRA, H. B. B.; CUNHA, I. B. A.; GARCIA, J. C. R.; ALBUQUERQUE, J. P. S.; NEVES, J. T. R.; FERREIRA, J. S.; FERREIRA, L. B.; KAVA, L.; CAMBOIM, L. G.; FREIRE, M.; VITORIANO, M. C. C. P.; TARGINO, M. G.; FREITAS, M. C. D.; SAVI, M. G. M; FROTA, M. G. C.; LIMA, M. J. C.; FREITAS, M. C.; FIDELIS, M. B.; CARVAJAL, M. P.; R. O. A, M. M.; DUTRA, M.; ROCKEMBACH, M.; LIMA JÚNIOR, O. P.; ALMEIDA JÚNIOR, O. F.; QUINTÃO, P. G.; BARBOSA NETO, P. A.; BELUZZO, R. C. B.; SAMPAIO, R. R.; SANT'ANA, R. C. G.; MELLO, R. C.; BOTELHO FRANCISCO, R. E.; MEIRELLES, R. F.; BONATTI, R. A.; ARAÚJO JÚNIOR, R. H.; PAIVA, S. B.; SEMENSATTO, S.; BINOTTO, S. F. T.; LIMA, S. R.; REBOUÇAS, T.; FERNANDES, T. F. S.; TEIXEIRA, T. M. C.; MORIGI, V. J.; SILVA, V. J.; SANTARÉM, V.; ANDRADE, W. O.; GUEDES, W. e CUNHA, F. J. A. P.

Fonte: Dados da pesquisa (2020)

Na Tabela 1 verificou-se o quantitativo de artigo por autor, o que explica a centralidade dos atores na rede, pois estes sujeitos dominantes detêm o maior quantitativo de produções, o que impacta significativamente no número de relações e na dimensão dos subgrupos observados.

Em sua totalidade são 86 atores em interação, 70 deles produziram um artigo cada, 13 atores produziram dois artigos. $\mathrm{O}$ ator RADOS, G. J. V., produziu oito artigos, VALENTIM, M. L. P., seis e INOMATA, D. O., publicou três artigos indexados na Brapci no período pesquisado.

Os resultados demonstraram que o quantitativo de artigos pode ser um fator determinante no papel de um ator dentro de uma estrutura social, neste caso, na produção e construção do conhecimento científico. Mas, é fundamental que este esteja em constante comunicação com outros atores, estabelecendo um processo de troca, pois, "A comunicação científica ocorre quando as relações entre as pessoas e entre as instituições se estabelecem, à medida que se estabelecem as articulações entre os pares e dos pares com a sociedade. [...]" (PISCIOTTA, 2006, p. 117).

O Grafo 2 demonstra a composição da rede social por vínculo institucional de coautores com artigos sobre fluxos de informação indexados na Brapci.

A composição da rede social por vínculo institucional de coautores representa a participação dos pesquisadores vinculados a 23 instituições, sendo 22 no Brasil e uma na Espanha.

As instituições localizadas no Brasil e ordenadas por região foram: Região Nordeste (12): Fundação Visconde de Cairú - FAVIC-BA; Instituto de Ensino Superior Franciscano (IESF); Instituto Recôncavo de Tecnologia-Bahia (IRT-BA); Universidade Católica do Salvador (UCSal); Universidade Estadual do Ceará (UECE); Universidade Estadual da Paraíba (UEPB); Universidade Estadual de Feira de Santana (UEFS); Universidade Federal da Bahia (UFBA); Universidade Federal da Paraíba (UFPB); Universidade Federal de Pernambuco (UFPE); Universidade Federal do Piauí (UFPI); Universidade Federal do Rio Grande do Norte (UFRN); Região Sul: Instituto Federal Catarinense (IFC); Universidade Federal do Paraná (UFPR); Universidade Federal do Rio Grande do Sul (UFRGS); Universidade Federal de Santa Catarina (UFSC); Região Sudeste (5): Instituto Brasileiro de Informação Científica e Tecnológica (IBICT); Pontifícia Universidade Católica (PUC-Campinas); Universidade Federal de Minas Gerais (UFMG); Universidade Estadual de São Paulo (UNESP); Universidade Federal do Rio de Janeiro (UFRJ); Centro-Oeste (1): Universidade de Brasília (UnB).

Perspectivas em Gestão \& Conhecimento, João Pessoa, v. 10, número especial, p. 136-159, mar. 2020. 
Grafo 2 - Rede social de vínculo institucional dos coautores com artigos sobre fluxos de informação indexados na Brapci (2000 a 2019)

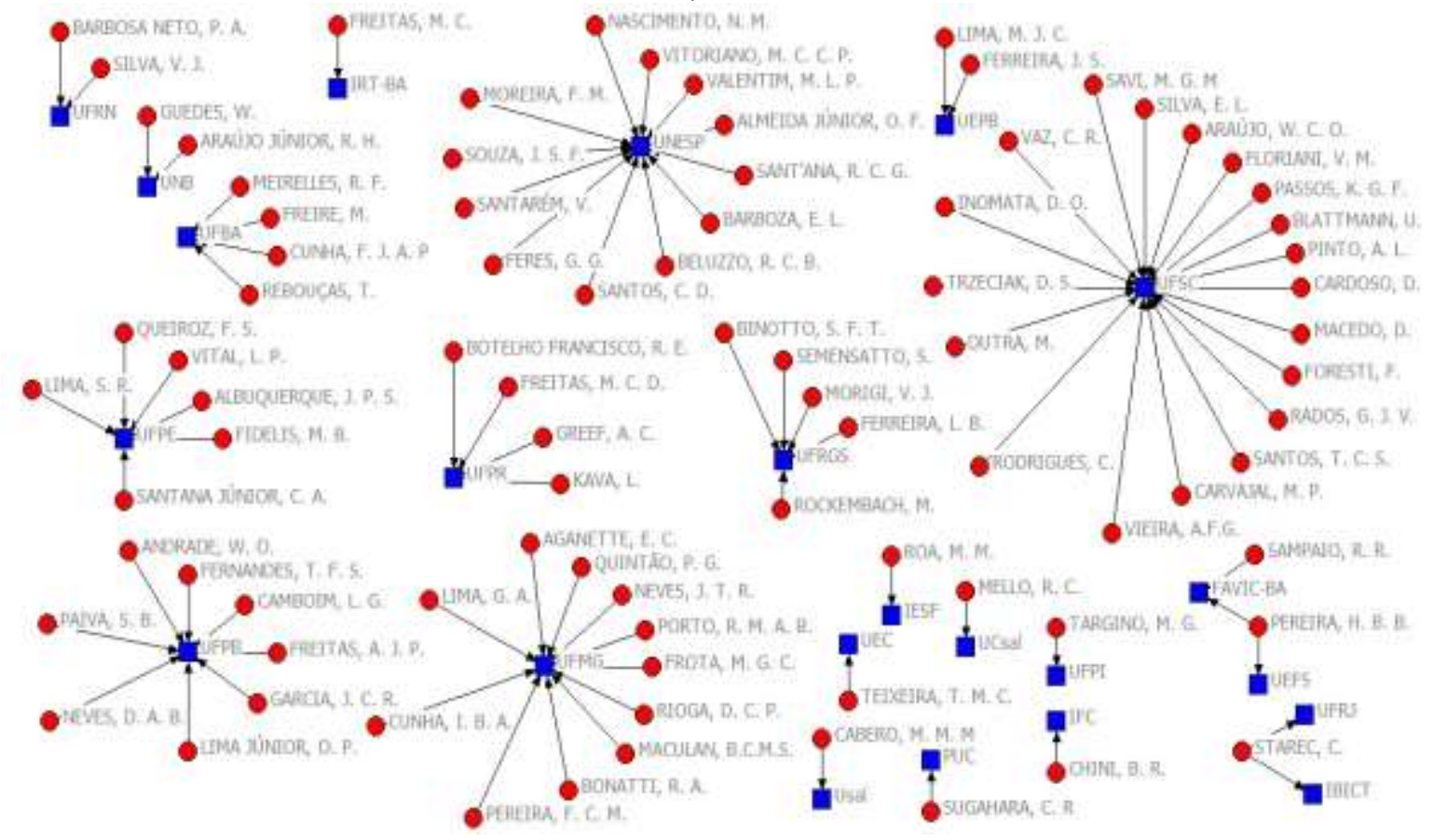

Fonte: Dados da Pesquisa, 2019

A instituição internacional, localizada na Espanha, foi a Universidad de Salamanca (USal). O interesse comum no tema "fluxos de informação" dos atores partícipes dessas instituições potencializa a constituição de redes temáticas organizadas por região, refletindo uma endogenia institucional existente por razões geográficas e de proximidade. Os destaques relacionados ao vínculo institucional podem ser consultados na nota de rodapé2.

Verificou-se, também, significativa participação de atores com vínculo com a UFPB, totalizando oito atores (ANDRADE, W. O.; CAMBOIM, L. G.; FERNANDES, T. F. S.; FREITAS, A. J. P.; GARCIA, J. C. R.; LIMA JÚNIOR, O. P.; NEVES, D. A. B. e PAIVA, S. B.) e a UFPE com seis atores. A UFRGS apresentou-se com cinco atores (BINOTTO, S. F. T.; SEMENSATTO, S.; MORIGI, V. J.; FERREIRA, L.B. e ROCKEMBACH, M.).

Os resultados demonstraram que a UFPR (BOTELHO FRANCISCO, R. E.; FREITAS, M. C. D., GREEF, A. C. e KAVA, L.) e UFBA (MEIRELlES, R. F.; FREIRE M.; CUNHA, F. J. A. P. e REBOUÇAS, T.) tiveram a mesma quantidade de nós, quatro atores cada.

$\mathrm{Na}$ rede de vínculo institucional, outras 11 instituições foram identificadas, cada uma contou com a participação de apenas um ator, evidenciando-se a necessidade de maior comunicação e interação entre os atores que pesquisam e publicam sobre o tema "fluxos informacionais", seja por interações intrainstitucionais ou interinstitucionais, a fim de

${ }^{2}$ UFSC com 19 atores (PINTO, A. L.; VIEIRA, A.F.G.; VAZ, C. R.; RODRIGUES, C.; CARDOSO, D., INOMATA, D. O.; TRZECIAK, D. S.; MACEDO, D.; SILVA, E. L.; FORESTI, F.; RADOS, G. J. V.; PASSOS, K. G. F.; SAVI, M. G. M.; CARVAJAL, M. P.; DUTRA, M.; SANTOS, T. C. S.; BLATTMANN, U.; FLORIANI, V. M.; e ARAÚJO, W. C. O.); UNESP com 12 atores (SANTOS, C. D.; BARBOZA, E. L.; MOREIRA, F. M.; FERES, G. G.; SOUZA, J. S. F.; VITORIANO, M. C. C. P.; VALENTIM, M. L. P.; NASCIMENTO, N. M.; ALMEIDA JÚNIOR, O. F.; BELUZZO, R. C. B.; SANT'ANA, R. C. G. e SANTARÉM, V.) e; UFMG com 11 atores (MACULAN, B.C.M.S.; RIOGA, D. C. P.; AGANETTE, E. C.; PEREIRA, F. C. M.; LIMA, G. A.; CUNHA, I. B. A.; NEVES, J. T. R.; FROTA, M. G. C.; QUINTÃO, P. G.; PORTO, R. M. A. B. e BONATTI, R. A.).

Perspectivas em Gestão \& Conhecimento, João Pessoa, v. 10, número especial, p. 136-159, mar. 2020. 
estabelecer novas parcerias, discussões temáticas e ampliação da rede social. Afinal, "[...] a cooperação, as parcerias e a adoção de redes de comunicação possibilitam a interação. A interação leva ao compartilhamento, impulsiona os fluxos de informação e conhecimento [...]" (TOMAÉL, 2008, p. 1).

O Gráfico 1 ilustra a quantidade de artigos indexados na Brapci com o tema "fluxos de informação".

Gráfico 1 - Quantidade de artigos sobre fluxos de informação indexados por ano na Brapci (2000 a 2019)

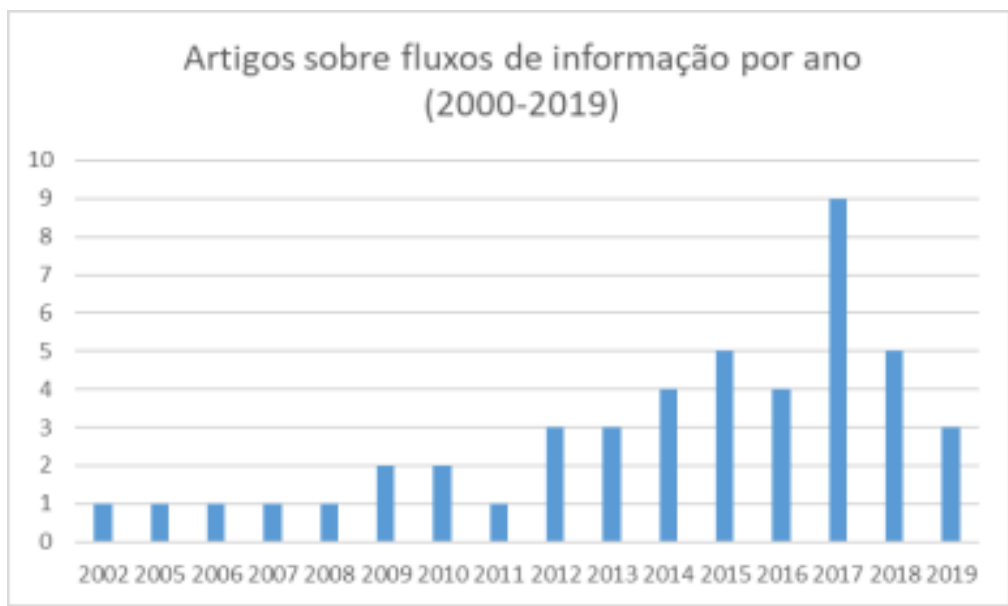

Fonte: Dados da pesquisa, 2020

Percebeu-se que a maior incidência de artigos sobre fluxos de informação indexados na Brapci ocorreu no ano 2017, com oito publicações recuperadas. Por outro lado, esta tendência ascendente não se manteve a partir de 2018, como ocorreu no período 2013 a 2015, com redução de oito para três artigos. Já entre os anos 2002 e 2008, observou-se o comportamento de uma publicação por ano, dado que se repetiu em 2011.

Por meio dos artigos recuperados, identificou-se que os atores têm demonstrado interesse por estudos sobre os fluxos de informação, tendo em vista que em duas décadas, apenas em 2000, 2001, 2003 e 2004 não foram recuperados artigos indexados na Brapci sobre o tema.

O conjunto de artigos recuperados, com título, autoria, instituição, ano de publicação e periódico de origem está apresentado no Apêndice desse artigo.

O Gráfico 2 ilustra a quantidade de artigos por periódicos indexados na Brapci, demonstrando aqueles que mais publicam sobre o tema.

Percebeu-se maior ocorrência de publicações no periódico Perspectivas em Gestão \& Conhecimento com sete artigos (15,22\%), sendo três deles publicados em 2017. Em seguida, o periódico Encontros Bibli com 5 artigos (10,87\%) e Pesquisa Brasileira em Ciência da Informação e Biblioteconomia - PBClB com 4 artigos (8,69\%).

De acordo com os dados dispostos, os periódicos mencionados vêm se constituindo como fontes de informação consagradas na Cl brasileira no assunto "fluxos de informação", em especial, dentre os veículos indexados na Brapci. 
Gráfico 2 - Quantidade de artigos por periódico indexados na Brapci (2000 a 2019)

\section{Quantidade de Artigos por Periódico}

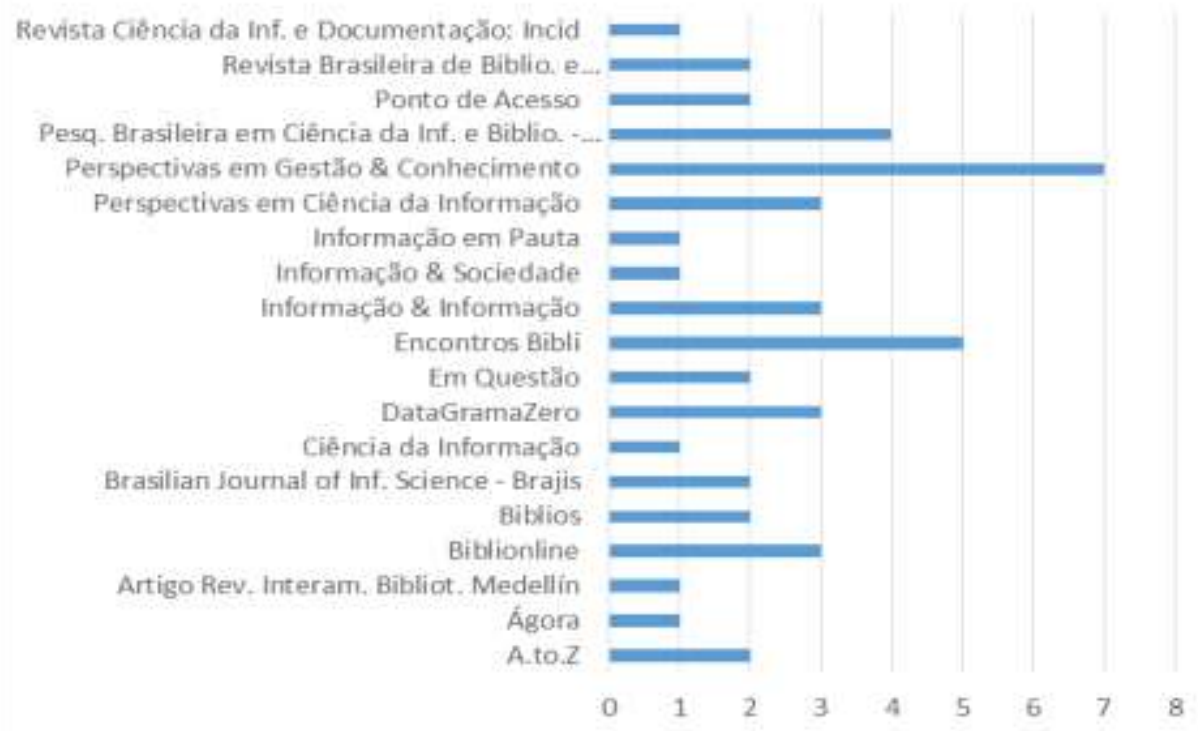

Fonte: Dados da Pesquisa, 2019

As análises revelaram que os periódicos Biblionline, DataGramaZero, Informação \& Informação e Perspectivas em Ciência da Informação tiveram a mesma quantidade de artigos indexados na Brapci, dispondo cada um de três publicações sobre o tema pesquisado. Chama a atenção o destaque do DataGramaZero, mesmo tendo sido descontinuado.

A.to.Z., Biblios, Brazilian Journal of Inf. Science (Brajis), Em Questão, Ponto de Acesso e Revista Brasileira de Biblioteconomia e Documentação (RBBD), tiveram, cada uma, dois artigos indexados na Brapci sobre fluxos de informação.

Os periódicos com apenas um artigo indexado foram: Ágora, Artigo Rev. Interam. Bibliot. Medellin, Ciência da Informação, Informação \& Sociedade, Informação em Pauta e Revista Ciência da Inf. e Documentação (Incid).

Este levantamento totalizou 46 artigos recuperados e revelou também os periódicos que a Brapci indexa e que contemplam publicações sobre o tema. Vale ressaltar que como a Brapci é uma base de dados indexadora, nos periódicos citados pode haver outras publicações sobre o tema. Não foi objeto fazer essa busca, uma vez que a Brapci constituiu a fonte de coleta de dados dessa pesquisa, sendo considerada uma base de referência e excelência na comunidade de $\mathrm{Cl}$.

Apresenta-se no Grafo 3 com a sub-rede dos temas associados a "fluxos de informação" considerando a pesquisa na Brapci. 
Grafo 3 - Rede dos subtemas correlacionados com "fluxos de informação" identificados nos artigos recuperados na Brapci (2000-2019)

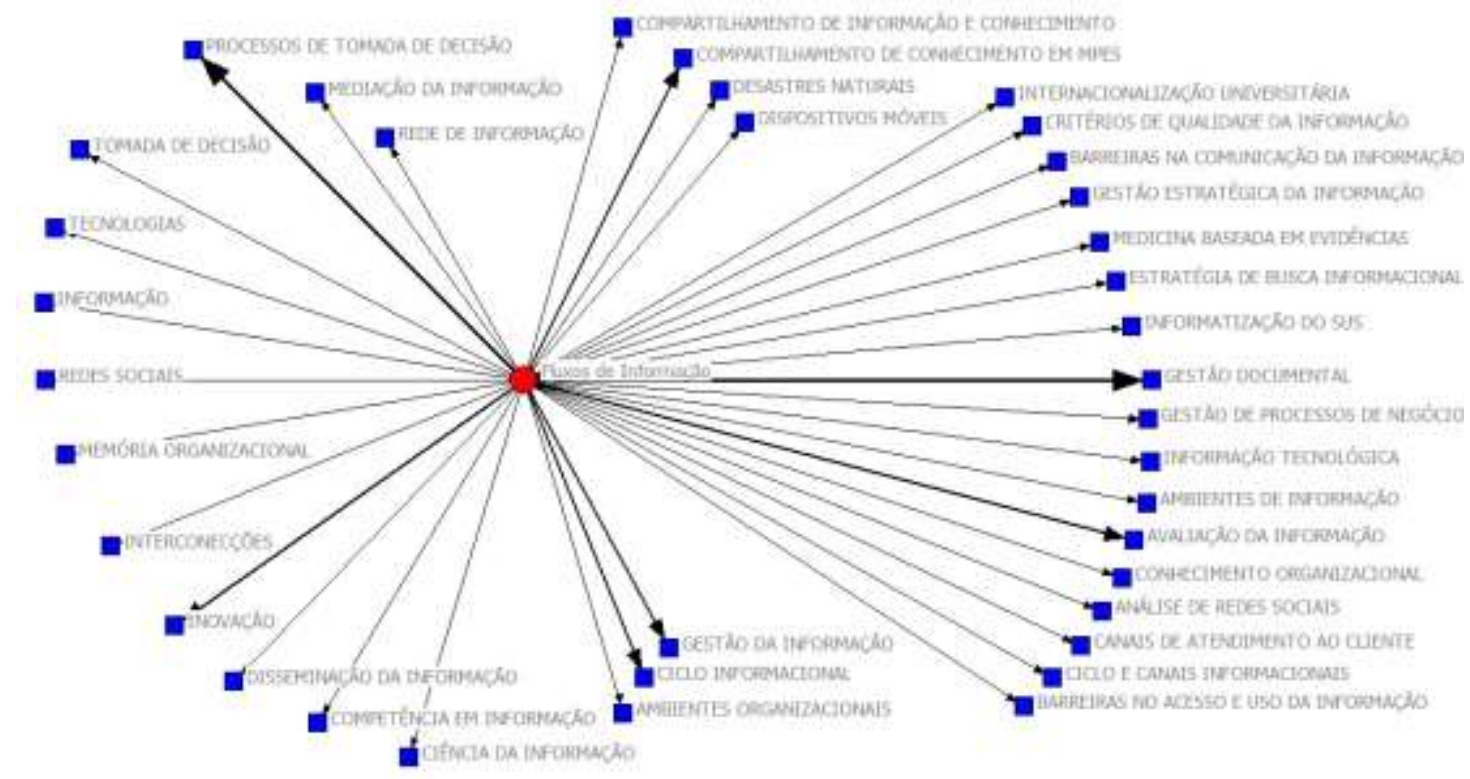

Fonte: Dados da Pesquisa (2019)

Nas pesquisas analisadas se identificaram que os estudos sobre fluxos de informação estão relacionados a outros 37 temas associados. Isto demonstrou a relevância que este tema tem no que se refere à abrangência e as relações interdisciplinares que estabelece, tendo múltiplas abordagens e aplicações. Fazendo uma breve análise, constataram-se: 25 artigos de cunho teórico, 13 aplicados e oito híbridos, com abordagem teórico-prática.

Os termos coocorrentes ao assunto "fluxos de informação" mais expressivos foram: processos de tomada de decisão (4), gestão documental (3), avaliação da informação (2), gestão da informação (2), ciclo informacional (2), inovação (2) e compartilhamento de conhecimento em MPEs (2). Esses temas estabeleceram laços fortes na rede por relacionarem-se com o tema fluxos de informação mais de uma vez, sendo a relação com processo de tomada da decisão e gestão documental as mais intensas devido à quantidade de vezes que foram abordados nos estudos. Os demais temas relacionados foram identificados apenas uma vez, podendo ser ampliados em novos estudos a partir do avanço da produção sobre fluxos de informação.

Acredita-se que as principais relações temáticas supramencionadas têm relação com os contextos arquivísticos e de gestão documental, que se baseiam na aplicação de workflows para o mapeamento de fluxos de documentos, especialmente, voltando-se à construção de sistemas de informação próprios a este fim. Neste contexto, destaca-se também a avaliação de documentos, enquanto uma das funções arquivísticas propostas por Rousseau e Couture (1998), com o propósito de controlar os documentos para impedir seu crescimento demasiado em número e volume, conforme destacam Santos e Flores (2016).

Em geral, nos estudos sobre os fluxos informacionais, buscam-se soluções para processos de gestão da informação e de documentos, partindo do pressuposto que estes processos demandam padronização e a existência de fluxos bem definidos, visando beneficiar diversos contextos institucionais, seja no âmbito da memória organizacional, da inteligência competitiva ou da gestão do conhecimento. Em suma, as relações encontradas acima apresentam indícios da aplicação de fluxos informacionais como insumo para a tomada de

Perspectivas em Gestão \& Conhecimento, João Pessoa, v. 10, número especial, p. 136-159, mar. 2020. 
decisão e para o processo de inteligência competitiva organizacional. (VALENTIM; SOUZA, 2013).

\section{CONSIDERAÇÕES FINAIS}

Neste artigo foi estudada a análise das redes de coautoria sobre fluxos de informação em artigos de periódicos indexados pela Brapci entre os anos de 2000 a 2019. As redes sociais estão presentes nos mais diversos aspectos da vida, sejam nas relações de trabalho, acadêmicas, entre outras. A análise das redes sociais na comunicação científica justifica-se pelo fato de conhecer o que vem sendo publicado, quem são os atores associados, qual a intensidade dessas relações, se o assunto está sendo estudado e publicado com afinco, suas relações, abordagens temáticas etc.

Com base no estudo, obtiveram-se os seguintes resultados acerca da rede de coautoria sobre o tema fluxos de informação: foram contabilizados 86 atores de 23 instituições, sendo uma internacional. O Nordeste despontou em número de instituições que publicaram sobre o tema (12), sendo a UFPB e a UFPE as Universidades com maior número de atores nessa região, 8 e 6 respectivamente. No geral, em termos de vínculo institucional, a UFSC (19), a UNESP (12) e UFMG (11) se sobressaíram no período como as instituições que mais agregaram atores.

$\mathrm{O}$ ator RADOS, G. J. V., da UFSC publicou oito artigos; VALENTIM, M. L. P., da UNESP seis artigos; e INOMATA, D. O., da UFSC produziu três artigos. RADOS, G. J. V., apresentou vínculo relacional com nove atores e maior nível de intensidade de relações com o ator INOMATA, D. O. (juntos publicaram três artigos). VALENTIM, M. L. P., apresentou vínculo relacional com sete atores e maior nível de intensidade de relação com os atores CABERO, $M$. M. M., e NASCIMENTO, N. M. (publicaram dois artigos com cada ator). Ressalta-se que essa rede é predominantemente intrainstitucional. A UFSC apresentou-se como a que tem mais artigos indexados na Brapci de 2000 a 2019.

Os artigos analisados (46) foram publicados em 19 periódicos, sendo a Perspectivas em Gestão \& Conhecimento da UFPB, a mais representativa no quantitativo de publicações sobre fluxos de informação no período pesquisado (sete artigos). Dentre a relação dos 37 temas coocorrentes em relação a fluxos de informação, evidenciaram-se os processos de tomada de decisão e a gestão documental como os assuntos mais expressivos.

Dos anos 2000 a 2011 foram indexados poucos artigos sobre fluxos de informação (um ou dois por ano), porém, a partir de 2012 notou-se o crescimento no número de publicações (de três a oito por ano), levando a entender que os estudos sobre o tema têm se intensificado nesse período. Trata-se de um assunto que envolve a $\mathrm{Cl}$, bem como a área de Administração/Gestão, pois, trabalham com a informação, que constitui um recurso estratégico para o crescimento e fortalecimento organizacional, estudando-se as melhores maneiras de potencializar e melhorar sua circulação e uso.

Vale ressaltar que pesquisas em outros tipos de publicações e em outras fontes podem ser realizadas, já que os processos de produção, busca e acesso a informação são dinâmicos e precisam de estudos sobre seu fluxo dentro do processo de comunicação científica.

\section{REFERÊNCIAS}

ARAÚJO, Wánderson Cássio Oliveira; SILVA, Edna Lúcia da; VARVAKIS, Gregório. Fluxos de informação em projetos de inovação: estudo em três organizações. Perspectiva em Ciência da Informação, v.22, n.1, p. 57-79, jan./mar. 2017. Disponível em: 
http://www.scielo.br/pdf/pci/v22n1/1413-9936-pci-22-01-00057.pdf. Acesso em: 07 dez. 2019.

BARRETO, Aldo de Albuquerque. A condição da informação. In: STAREC, Claudio; GOMES, Elizabeth; BEZERRA, Jorge. (orgs.). Gestão estratégica da Informação e Inteligência competitiva. São Paulo: Saraiva, 2005. p.20-35.

BEAL, Adriana. A gestão estratégica da informação: como transformar a informação e a tecnologia da informação em fatores de crescimento e auto desempenho nas organizações. 4. ed. São Paulo: Atlas, 2004. 137 p.

BRAGA, Mauro Joaquim da Costa; GOMES, Luiz Flavio Autran Monteiro; RUEDIGER, Marco Aurélio. Mundos pequenos, produção acadêmica e grafos de colaboração: um estudo de caso dos Enanpads. RAP - Revista de Administração Pública, Rio de Janeiro, v. 42, n. 1, p.133-154, jan. 2008. Disponível em: http://www.scielo.br/pdf/rap/v42n1/a07v42n1. Acesso em: $01 \mathrm{fev}$. 2019.

BRAPCI. Busca. Curitiba, PR, janeiro de 2019. Disponível em: http://www.Brapci.inf.br/index.php/res/help. Acesso em: 19 jan. 2019.

CAREGNATO, Célia Elizabete et al. Avaliação de redes de pesquisa e colaboração. Avaliação, Campinas; Sorocaba, SP, v. 19, n. 1, p. 291-312, mar. 2014. Disponível em: $<$ http://periodicos.uniso.br/ojs/index.php/avaliacao/article/view/1851. Acesso em: $07 \mathrm{dez}$. 2019.

CASTELLS, Manuel. O espaço de fluxos. In: CASTELLS, Manuel. A sociedade em rede. 6 . ed. Rio de Janeiro: Paz e Terra, 2001. v. 1. Cap. 6. p. 467-521.

FERNANDES, Tatiana de Souza Falcão. Fluxo informacional em canais de atendimento ao cliente: estudo de caso nos Correios da Paraíba. 2013. 157 p. Dissertação (Mestrado em Ciência da Informação) - Programa de Pós-Graduação em Ciência da Informação, Universidade Federal da Paraíba, João Pessoa, 2013. Disponível em: https://repositorio.ufpb.br/jspui/bitstream/tede/3949/1/arquivototal.pdf. Acesso em: 19 jan. 2019.

FERNANDES, Tatiana de Souza Falcão; GARCIA, Joana Coeli Ribeiro. Fluxo informacional dos canais de atendimento ao cliente da empresa brasileira de Correios e Telégrafos. Brazilian Journal of Information Science, Marília, v.7, n. especial, p.103-111, 10 sem. 2013. Disponível em: http://www2.marilia.unesp.br/revistas/index.php/bjis/article/view/3121. Acesso em: 19 jan. 2019.

GIL, Antônio C. Como elaborar projetos de pesquisa. São Paulo: Atlas, 2010.

GONZALEZ AGUILAR, Audilio et al. Visualização de redes. In: GONZALEZ AGUILAR, Audilio et al. Visualização de dados, informação e conhecimento. Florianópolis: Editora UFSC, 2017. Cap. 8. p. 191-210. 
HAYTHORNTHWAITE, Caroline. Redes de aprendizagem, grupos e comunidades. In: TOMAEL, Maria Inês; MARTELETO, Regina Maria. Informação e redes sociais: interfaces de teorias, métodos e objetos. Londrina: Eduel, 2015. p. 41-58.

INOMATA, Danielly Oliveira. et al. Barreiras ao acesso e uso da informação: evidências em projetos de inovação. Brazilian Journal of Information Science, Marília, v.11, n.1, p.79-89, jan./mai. $2017 . \quad$ Disponível em: http://www2.marilia.unesp.br/revistas/index.php/bjis/article/view/5147. Acesso em: 19 jan. 2019.

INOMATA, Danielly Oliveira; RADOS, Gregório Jean Varvakis. A complexidade do fluxo da informação tecnológica e a interação da rede interna no subsídio ao desenvolvimento de produtos biotecnológicos. Biblios: Revista Electrónica de Bibliotecología, Archivología y Museología, n. 58, p. 1-16, $2015 . \quad$ Disponível em: https://dialnet.unirioja.es/servlet/articulo?codigo=5072801. Acesso em: 07 dez. 2019.

LARA, Marilda Lopes Ginez; LIMA, Vânia Mara Alves. Fundamentação básica para análise de redes sociais. In: POBLACIÓN, Dinah Aguiar; MUGNAINI, Rogério. RAMOS, Lucia Maria S. V. Costa. Redes sócias e colaborativas em informação científica. São Paulo: Angellara, 2009. p. 605-637.

LEMIEUX, Vicent; OUIMET, Mathieu. Análise estrutural das redes sociais. Lisboa: Instituto Piget, 2008.

NASCIMENTO, Natália Marinho do et al. Gerenciamento dos fluxos de informação com requisito para a apresentação da memória organizacional: um diferencial competitivo. Perspectiva em Gestão \& Conhecimento, João Pessoa, v.6, Número Especial, p. 29-44, jan.2016. Disponível em: http://www.Brapci.inf.br/index.php/res/download/56893. Acesso em: 7 dez. 2019.

NASCIMENTO, Natália Marinho do; VALENTIM, Marta Lígia Pomin; CABERO, María Manuela Moro. Reflexões a partir das análises bibliométricas sobre tipos documentais, fluxos informacionais e avaliações de documentos. Encontros Bibli: revista brasileira de biblioteconomia e ciência da informação, Florianópolis, v.22, n.50, p.59-75, set./dez., 2017. Disponivel em: $\quad$ https://periodicos.ufsc.br/index.php/eb/article/view/15182924.2017v22n50p59/34695. Acesso em: 19 jan. 2019.

PISCIOTTA, Kátia; Redes sociais: articulação com os pares e com a sociedade. In: POBLACIÓN, Dinah Aguiar; MUGNAINI, Rogério. RAMOS, Lucia Maria S. V. Costa. Redes sociais e colaborativas em informação científica. São Paulo: Angellara, 2006. p. 117-135.

ROUSSEAU, Jean-Yves; COUTURE, Carol. Os Fundamentos da disciplina arquivística. Lisboa: Publicações Dom Quixote, 1998.

RUAS, Wilimar Júnior; FERREIRA, Marta Araújo Tavares. Análise de citações e análise de redes sociais: rede de referências em educação científica no portal de periódicos capes. Revista ACB: Biblioteconomia em Santa Catarina, Florianópolis, v.21, n.1, p.156-166, dez./mar., 2016. Disponível em: https://revista.acbsc.org.br/racb/article/view/1061/pdf. Acesso em: 19 jan. 2019.

Perspectivas em Gestão \& Conhecimento, João Pessoa, v. 10, número especial, p. 136-159, mar. 2020. 
SANTARÉM, Vinicius; VITORIANO, Márcia Cristina de Carvalho Pazin. Gestão da informação, fluxos de informacionais e memória organizacional como elementos da inteligência competitiva. Perspectivas em Gestão \& Conhecimento, João Pessoa, v.5, número especial, p.158-170, jan. 2016.2 Disponível em: http://www.periodicos.ufpb.br/ojs/index.php/pgc/article/view/27387/14781. Acesso em: 19 jan. 2019.

SANTOS, Henrique Machado dos; FLORES, Daniel. O documento digital no contexto das funções arquivísticas. Páginas a\&b: arquivos e bibliotecas, p. 165-177, 2016. Disponível em: https://pentaho.letras.up.pt/ojs/index.php/paginasaeb/article/view/1477. Acesso em: 19 jan. 2019.

SAVI, Maria Gorete Monteguti; SILVA, Edna Lúcia da. O fluxo da informação na prática clínica dos médicos residentes: análise na perspectiva da medicina baseada em evidências. Ciência da Informação, Brasília, v.38, n.3, p.177-191, set./dez., 2009. Disponível em: http://www.Brapci.inf.br/index.php/article/download/10340. Acesso em: 19 jan. 2019.

SILVA, Alzira Karla Araújo da. Redes de Co-autoria e Produção Científica em Ciência da Informação. João Pessoa: Editora da UFPB, 2015.

SILVA, Alzira Karla Araújo; CÂMARA, Rafael Silva da; BARROS, Kelly Cristiane Queiroz. Evolução dos estudos sobre temática 'redes' entre pesquisadores do GT 7 nos ENANCIBs (2011 a 2016). Perspectivas em Ciência da Informação, Belo Horizonte, v.22, n.4, p.140-156, out./dez., 2017. Disponível em: http://www.scielo.br/pdf/pci/v22n4/1413-9936-pci-22-04-00140.pdf. Acesso em: 19 jan. 2019.

SOUSA, Paulo de Tarso Costa de. Metodologia de análise de redes sociais. In: MUELLER, Suzana Pinheiro Machado. Métodos para a pesquisa em Ciência da Informação. Brasília: Thesaurus, 2007. p. 119-149.

STAREC, Claudio. Informação e Universidade: os pecados informacionais e barreiras na comunicação da informação para tomada de decisão na universidade. DataGramaZero Revista de Ciência da Informação, Rio de Janeiro, v.3, n.4, p.1-10, ago., 2002. Disponível em: http://www.Brapci.inf.br/index.php/article/download/7486. Acesso em: 19 jan. 2019.

TOMAÉL, Maria Inês. Redes de conhecimento. DataGramaZero - Revista de Ciência da Informação, v. 9, n.2, abr. 2008. Disponível em: http://www.brapci.inf.br/index.php/article/view/0000004919/0b15a5dac549009ddc296d048 bf9ae0f/. Acesso em: 06 dez. 2019.

VALENTIM, Marta Lígia Pomin. Ambientes e Fluxos de informação. São Paulo: Cultura Acadêmica, 2010. 282 p.

VALENTIM, Marta Lígia Pomin; SOUZA, Juliete Susann Ferreira. Fluxos de informação que subsidiam o processo de inteligência competitiva. Encontros Bibli: revista eletrônica de biblioteconomia e ciência da informação, v. 18, n. 38, p. 87-106, set./dez., 2013. Disponível em: https://periodicos.ufsc.br/index.php/eb/article/view/1518-2924.2013v18n38p87/25958. Acesso em: 06 dez. 2019.

Perspectivas em Gestão \& Conhecimento, João Pessoa, v. 10, número especial, p. 136-159, mar. 2020. 
VITAL, Luciane Paula; FLORIANI, Vivian Mengarda; VARVAKIS, Gregório. Gerenciamento do fluxo de informação como suporte ao processo de tomada de decisão. Informação \& Informação, Londrina, v.15, n.1, p.85-103, jun./jul.,2010. Disponível em: http://www.uel.br/revistas/uel/index.php/informacao/article/view/5335/5880. Acesso em: 19 jan. 2019.

WITTER, Geraldina Porto. Redes sociais e sistemas de informação na formação do pesquisador. In: POBLACIÓN, Dinah Aguiar; MUGNAINI, Rogério. RAMOS, Lucia Maria S. V. Costa. Redes sociais e colaborativas em informação científica. São Paulo: Angellara, 2009, p. 169-201.

Artigo recebido em 09/12/2019 e aceito para publicação em 27/02/2020 
APÊNDICE A - Artigos recuperados na Brapci sobre fluxos de informação (2000 a 2019)

\begin{tabular}{|c|c|c|c|c|}
\hline Título do artigo & Autor(es) & Instituição & Ano & Periódico \\
\hline $\begin{array}{l}\text { Informação e Universidade: os } \\
\text { pecados informacionais e } \\
\text { barreiras na comunicação da } \\
\text { informação para a tomada de } \\
\text { decisão na universidade }\end{array}$ & STAREC, C. & IBICT/UFRJ & 2002 & Data Grama Zero \\
\hline $\begin{array}{l}\text { Estudo das disfunções do fluxo } \\
\text { de informação do arquivo do } \\
\text { departamento financeiro da } \\
\text { empresa Z. S/A: aplicação da } \\
\text { técnica 5w2h. }\end{array}$ & $\begin{array}{l}\text { LIMA JÚNIOR, O. P.; } \\
\text { FREITAS, A. J. P }\end{array}$ & $\begin{array}{l}\text { UFPB } \\
\text { UFPB }\end{array}$ & 2005 & Biblionline \\
\hline $\begin{array}{l}\text { Ciclo e fluxo informacional nas } \\
\text { festas comunitárias }\end{array}$ & $\begin{array}{l}\text { MORIGI, V. J.; } \\
\text { SEMENSATTO, S.; } \\
\text { BINNOTO, S. F. T. }\end{array}$ & $\begin{array}{l}\text { UFRGS } \\
\text { UFRGS } \\
\text { UFRGS }\end{array}$ & 2006 & $\begin{array}{l}\text { Informação e } \\
\text { Sociedade }\end{array}$ \\
\hline $\begin{array}{l}\text { Fluxos de informações e } \\
\text { conhecimentos para inovações } \\
\text { no arranjo produtivo local de } \\
\text { confecções em Salvador, Bahia }\end{array}$ & $\begin{array}{l}\text { PEREIRA, H. B. B; } \\
\text { FREITAS, M. C; } \\
\text { SAMPAIO, R.R. }\end{array}$ & $\begin{array}{l}\text { FAVIC/UEFS } \\
\text { IRT } \\
\text { FAVIC }\end{array}$ & 2007 & Data Grama Zero \\
\hline $\begin{array}{l}\text { O fluxo informacional nos } \\
\text { laboratórios de análises clínicas } \\
\text { em salvador }\end{array}$ & $\begin{array}{l}\text { MELLO, R. C; } \\
\text { REBOUÇAS, T. }\end{array}$ & $\begin{array}{l}\text { UCSal; } \\
\text { UFBA }\end{array}$ & 2008 & Ponto de Acesso \\
\hline $\begin{array}{l}\text { Competência em informação: } \\
\text { um diferencial da qualidade em } \\
\text { publicações científicas }\end{array}$ & $\begin{array}{l}\text { FERES, G. G; } \\
\text { BELLUZZO, R. C. B. }\end{array}$ & $\begin{array}{l}\text { UNESP } \\
\text { UNESP }\end{array}$ & 2009 & $\begin{array}{l}\text { Revista Brasileira } \\
\text { de Biblioteconomia } \\
\text { e Documentação } \\
\text { (RBBD) }\end{array}$ \\
\hline $\begin{array}{l}\text { O fluxo da informação na } \\
\text { prática clínica dos médicos } \\
\text { residentes: análise na } \\
\text { perspectiva da medicina } \\
\text { baseada em evidências }\end{array}$ & $\begin{array}{l}\text { SAVI, M.G.M; } \\
\text { SILVA, E.L }\end{array}$ & $\begin{array}{l}\text { UFSC } \\
\text { UFSC }\end{array}$ & 2009 & $\begin{array}{l}\text { Ciência da } \\
\text { Informação }\end{array}$ \\
\hline $\begin{array}{l}\text { Gerenciamento do fluxo de } \\
\text { informação como suporte ao } \\
\text { processo de tomada de decisão }\end{array}$ & $\begin{array}{l}\text { VITAL, L. P.; } \\
\text { FLORIANI, V. M; } \\
\text { RADOS, G. J. V; }\end{array}$ & $\begin{array}{l}\text { UFPE/UFSC } \\
\text { UFSC } \\
\text { UFSC }\end{array}$ & 2010 & $\begin{array}{l}\text { Informação \& } \\
\text { Informação }\end{array}$ \\
\hline $\begin{array}{l}\text { Fluxos informacionais para o } \\
\text { monitoramento da convenção } \\
\text { dos direitos da criança: a } \\
\text { atuação da rede ngo group for } \\
\text { crc }\end{array}$ & $\begin{array}{l}\text { FROTA, M. G. C; } \\
\text { QUINTÃO, P. G. }\end{array}$ & $\begin{array}{l}\text { UFMG } \\
\text { UFMG }\end{array}$ & 2010 & Encontros Bibli \\
\hline $\begin{array}{l}\text { Uso das fontes de informação } \\
\text { para a geração de } \\
\text { conhecimento organizacional }\end{array}$ & $\begin{array}{l}\text { RODRIGUES, C. } \\
\text { BLATTMANN, U. }\end{array}$ & $\begin{array}{l}\text { UFSC } \\
\text { UFSC }\end{array}$ & 2011 & $\begin{array}{l}\text { Perspectivas em } \\
\text { Gestão \& } \\
\text { Conhecimento }\end{array}$ \\
\hline $\begin{array}{l}\text { Uso das fontes de informação } \\
\text { para a geração de } \\
\text { conhecimento organizacional }\end{array}$ & $\begin{array}{l}\text { VALENTIM, M. L. P. } \\
\text { TEIXEIRA, T. M. C. }\end{array}$ & $\begin{array}{l}\text { UNESP } \\
\text { UECE }\end{array}$ & 2012 & $\begin{array}{l}\text { Informação e } \\
\text { Sociedade }\end{array}$ \\
\hline $\begin{array}{l}\text { Usuários da informação } \\
\text { jurídica: quem são e como } \\
\text { funciona o fluxo informacional } \\
\text { no âmbito do arquivo da justiça } \\
\text { federal da paraíba (JFPB) }\end{array}$ & $\begin{array}{l}\text { NEVES, D. A. B. } \\
\text { ANDRADE, O. W. }\end{array}$ & $\begin{array}{l}\text { UFPB } \\
\text { UFPB }\end{array}$ & 2012 & Biblionline \\
\hline $\begin{array}{l}\text { Fluxo enxuto de informação: } \\
\text { um novo conceito }\end{array}$ & $\begin{array}{l}\text { GREEF, A. C; } \\
\text { FREITAS, M. C. D }\end{array}$ & $\begin{array}{l}\text { UFPR } \\
\text { UFPR }\end{array}$ & 2012 & $\begin{array}{l}\text { Perspectivas em } \\
\text { Ciência da }\end{array}$ \\
\hline
\end{tabular}

Perspectivas em Gestão \& Conhecimento, João Pessoa, v. 10, número especial, p. 136-159, mar. 2020. 
Alzira Karla Araújo da Silva; Barbara Carvalho Diniz; Flávia de Araújo Telmo; Natanael Vitor Sobral; Elaine Cristina de B. Moreira

\begin{tabular}{|c|c|c|c|c|}
\hline & & & & Informação \\
\hline $\begin{array}{l}\text { O fluxo de informação nas } \\
\text { instituições hospitalares e a } \\
\text { gestão de documentos }\end{array}$ & $\begin{array}{l}\text { FERREIRA, J. S; } \\
\text { FIDELIS, M. B; } \\
\text { LIMA, M. J. C }\end{array}$ & $\begin{array}{l}\text { UEPB } \\
\text { UFPE } \\
\text { UEPB }\end{array}$ & 2013 & Ágora \\
\hline $\begin{array}{l}\text { Fluxo informacional dos canais } \\
\text { de atendimento ao cliente da } \\
\text { empresa brasileira de correios } \\
\text { e telégrafos }\end{array}$ & $\begin{array}{l}\text { FERNANDES, T. F. S.; } \\
\text { GARCIA, J. C. R. }\end{array}$ & $\begin{array}{l}\text { UFPB } \\
\text { UFPB }\end{array}$ & 2013 & $\begin{array}{l}\text { Brazilian Journal of } \\
\text { Information } \\
\text { Science (BRAJIS) }\end{array}$ \\
\hline $\begin{array}{l}\text { Fluxos de informação que } \\
\text { subsidiam o processo de } \\
\text { inteligência competitiva }\end{array}$ & $\begin{array}{l}\text { VALENTIM, M. L. P; } \\
\text { SOUZA, J. S. F. }\end{array}$ & $\begin{array}{l}\text { UNESP } \\
\text { UNESP }\end{array}$ & 2013 & Encontros Bibli \\
\hline $\begin{array}{l}\text { O fluxo de informação sob a } \\
\text { ótica de gestores públicos em } \\
\text { turismo }\end{array}$ & $\begin{array}{l}\text { VITAL, L. P; } \\
\text { FLORIANI, V. M; } \\
\text { RADOS, G. J. V. }\end{array}$ & $\begin{array}{l}\text { UFSC } \\
\text { UFSC } \\
\text { UFSC }\end{array}$ & 2014 & $\begin{array}{l}\text { Informação \& } \\
\text { Informação }\end{array}$ \\
\hline $\begin{array}{l}\text { A disseminação da informação } \\
\text { no Twitter: uma análise } \\
\text { exploratória do fluxo } \\
\text { informacional de retweets }\end{array}$ & $\begin{array}{l}\text { SANTANA JÚNIOR, C. } \\
\text { A; } \\
\text { ALBUQUERQUE, J. P. } \\
\text { S; } \\
\text { QUEIROZ, F. S.; } \\
\text { LIMA, S. R. }\end{array}$ & $\begin{array}{l}\text { UFPE } \\
\text { UFPE } \\
\text { UFPE } \\
\text { UFPE }\end{array}$ & 2014 & A.to.Z \\
\hline $\begin{array}{l}\text { As interconexões entre a } \\
\text { gestão da informação e a } \\
\text { gestão do conhecimento para o } \\
\text { gerenciamento dos fluxos } \\
\text { informacionais }\end{array}$ & $\begin{array}{l}\text { SANTOS, C. D; } \\
\text { VALENTIM. M. L. P. }\end{array}$ & $\begin{array}{l}\text { UNESP } \\
\text { UNESP }\end{array}$ & 2014 & $\begin{array}{l}\text { Perspectivas em } \\
\text { Gestão \& } \\
\text { Conhecimento }\end{array}$ \\
\hline $\begin{array}{l}\text { O fluxo de informações na } \\
\text { auditoria pública e a teoria } \\
\text { Matemática da Comunicação }\end{array}$ & $\begin{array}{l}\text { GUEDES, W.; } \\
\text { ARAÚJO JÚNIOR, R. } \\
\text { H. }\end{array}$ & $\begin{array}{l}\text { UnB } \\
\text { UnB }\end{array}$ & 2014 & Encontros Bibli \\
\hline $\begin{array}{l}\text { A ubiquidade proporcionada } \\
\text { pelos dispositivos móveis e o } \\
\text { fluxo da informação }\end{array}$ & $\begin{array}{l}\text { VIEIRA, A. F. G.; } \\
\text { FORESTI, F. }\end{array}$ & $\begin{array}{l}\text { UFSC } \\
\text { UFSC }\end{array}$ & 2015 & Data Grama Zero \\
\hline $\begin{array}{l}\text { A complexidade do fluxo da } \\
\text { informação tecnológica e a } \\
\text { interação da rede interna no } \\
\text { subsídio ao desenvolvimento } \\
\text { de produtos biotecnológicos }\end{array}$ & $\begin{array}{l}\text { INOMATA, D. O; } \\
\text { RADOS, G. J. V. }\end{array}$ & $\begin{array}{l}\text { UFSC } \\
\text { UFSC }\end{array}$ & 2015 & Biblios \\
\hline $\begin{array}{l}\text { Análise da produção científica } \\
\text { brasileira sobre fluxos de } \\
\text { informação }\end{array}$ & $\begin{array}{l}\text { INOMATA, D. O; } \\
\text { ARAÚJO, W. C. O; } \\
\text { PASSOS, K. G. F; } \\
\text { RADOS, G. J. V. }\end{array}$ & $\begin{array}{l}\text { UFSC } \\
\text { UFSC/UFC } \\
\text { UFSC } \\
\text { UFSC }\end{array}$ & 2015 & Biblios \\
\hline $\begin{array}{l}\text { A gestão da informação e o } \\
\text { processo decisório no setor } \\
\text { energético: mensuração de } \\
\text { critérios e alternativas }\end{array}$ & $\begin{array}{l}\text { BONATTI, R. A; } \\
\text { PORTO, R. M. A. B. }\end{array}$ & $\begin{array}{l}\text { UFMG } \\
\text { UFMG }\end{array}$ & 2015 & $\begin{array}{l}\text { Pesquisa Brasileira } \\
\text { em Ciência da } \\
\text { Informação e } \\
\text { Biblioteconomia - } \\
\text { PBCIB }\end{array}$ \\
\hline $\begin{array}{l}\text { Análise do fluxo informacional } \\
\text { presente em uma empresa do } \\
\text { segmento de serviços de valor } \\
\text { agregado (SVA) }\end{array}$ & $\begin{array}{l}\text { CUNHA, I. B. A; } \\
\text { FREDERICO, C. M. P; } \\
\text { NEVES, J. T. R. }\end{array}$ & $\begin{array}{l}\text { UFMG } \\
\text { UFMG } \\
\text { UFMG }\end{array}$ & 2015 & $\begin{array}{l}\text { Perspectivas em } \\
\text { Ciência da } \\
\text { Informação }\end{array}$ \\
\hline $\begin{array}{l}\text { Gerenciamento dos fluxos de } \\
\text { informação como requisito } \\
\text { para a preservação da memória } \\
\text { organizacional: um diferencial }\end{array}$ & $\begin{array}{l}\text { NASCIMENTO, N. M.; } \\
\text { SOUZA, J. S. F.; } \\
\text { VALENTIM, M. L. P; } \\
\text { CABERO, M. M. M. }\end{array}$ & $\begin{array}{l}\text { UNESP } \\
\text { UNESP } \\
\text { UNESP } \\
\text { USal }\end{array}$ & 2016 & $\begin{array}{l}\text { Perspectivas em } \\
\text { Gestão \& } \\
\text { Conhecimento }\end{array}$ \\
\hline
\end{tabular}

Perspectivas em Gestão \& Conhecimento, João Pessoa, v. 10, número especial, p. 136-159, mar. 2020. 
Alzira Karla Araújo da Silva; Barbara Carvalho Diniz; Flávia de Araújo Telmo; Natanael Vitor Sobral;

Elaine Cristina de B. Moreira

\begin{tabular}{|c|c|c|c|c|}
\hline competitivo & & & & \\
\hline $\begin{array}{l}\text { Gestão documental em } \\
\text { instituições públicas: subsídios } \\
\text { e desafios para implantação de } \\
\text { uma política de acervo no } \\
\text { núcleo de prática jurídica da } \\
\text { UERN- Natal }\end{array}$ & $\begin{array}{l}\text { SILVA, V. J. } \\
\text { BARBOSA NETO, P. A. }\end{array}$ & $\begin{array}{l}\text { UFRN } \\
\text { UFRN }\end{array}$ & 2016 & Biblionline \\
\hline $\begin{array}{l}\text { Gestão estratégica da } \\
\text { informação em coordenações } \\
\text { de cursos de graduação de } \\
\text { universidades públicas federais }\end{array}$ & $\begin{array}{l}\text { CAMBOIM, L. G.; } \\
\text { PAIVA, S. B.; } \\
\text { TARGINO, M. G. }\end{array}$ & $\begin{array}{l}\text { UFPB } \\
\text { UFPB } \\
\text { UFPI }\end{array}$ & 2016 & $\begin{array}{l}\text { Perspectivas em } \\
\text { Gestão \& } \\
\text { Conhecimento }\end{array}$ \\
\hline $\begin{array}{l}\text { Gestão da informação, fluxos } \\
\text { informacionais e memória } \\
\text { organizacional como elementos } \\
\text { da inteligência competitiva }\end{array}$ & $\begin{array}{l}\text { SANTARÉM, V. } \\
\text { VITORIANO, M. C. C. } \\
\text { P. }\end{array}$ & $\begin{array}{l}\text { UNESP } \\
\text { UNESP }\end{array}$ & 2016 & $\begin{array}{l}\text { Perspectivas em } \\
\text { Gestão \& } \\
\text { Conhecimento }\end{array}$ \\
\hline $\begin{array}{l}\text { A gestão da informação } \\
\text { aplicada ao processo de } \\
\text { internacionalização } \\
\text { universitária: um estudo de } \\
\text { caso da UFMG }\end{array}$ & $\begin{array}{l}\text { RIOGA, D. C. P.; } \\
\text { PORTO, R. M. A. B. }\end{array}$ & $\begin{array}{l}\text { UFMG } \\
\text { UFMG }\end{array}$ & 2016 & $\begin{array}{l}\text { Pesquisa Brasileira } \\
\text { em Ciência da } \\
\text { Informação e } \\
\text { Biblioteconomia - } \\
\text { PBCIB }\end{array}$ \\
\hline $\begin{array}{lrr}\text { Narrativa no fluxo } & \text { de } \\
\text { informação } & \text { para } & \text { o } \\
\text { compartilhamento } & \text { de } \\
\text { conhecimento em } & \text { MPE: } \\
\text { proposta de um modelo } & \end{array}$ & $\begin{array}{l}\text { SANTOS, T. C. S.; } \\
\text { TRZECIAK, D. S.; } \\
\text { RADOS, G. J. V. }\end{array}$ & $\begin{array}{l}\text { UFSC } \\
\text { UFSC } \\
\text { UFSC }\end{array}$ & 2017 & $\begin{array}{l}\text { Perspectivas em } \\
\text { Gestão \& } \\
\text { Conhecimento }\end{array}$ \\
\hline $\begin{array}{l}\text { Barreiras ao acesso e uso da } \\
\text { informação: evidências em } \\
\text { projetos de inovação }\end{array}$ & $\begin{array}{l}\text { INOMATA, D. O.; } \\
\text { PASSOS, K. G. F.; } \\
\text { VAZ, C. R.; } \\
\text { RADOS, G. J. V. }\end{array}$ & $\begin{array}{l}\text { UFSC } \\
\text { UFSC } \\
\text { UFSC } \\
\text { UFSC }\end{array}$ & 2017 & $\begin{array}{l}\text { Brazilian Journal of } \\
\text { Science } \\
\text { Information } \\
\text { (BRAJIS) }\end{array}$ \\
\hline $\begin{array}{l}\text { Reflexões a partir da análise } \\
\text { bibliométrica sobre tipos } \\
\text { documentais, } \\
\text { informacionais e avaliação de } \\
\text { documentos }\end{array}$ & $\begin{array}{l}\text { NASCIMENTO, N. M.; } \\
\text { VALENTIM, M. L. P.; } \\
\text { CABERO, M. M. M. }\end{array}$ & $\begin{array}{l}\text { UNESP } \\
\text { UNESP } \\
\text { USal }\end{array}$ & 2017 & Encontros Bibli \\
\hline $\begin{array}{l}\text { Abordagens contemporâneas } \\
\text { sobre avaliação em } \\
\text { Arquivologia e Ciência da } \\
\text { Informação: macroavaliação, } \\
\text { avaliação do fluxo } \\
\text { informacional e modelo indício- } \\
\text { evidência-prova }\end{array}$ & $\begin{array}{l}\text { FERREIRA, L. B.; } \\
\text { ROCHEMBACH, M. }\end{array}$ & $\begin{array}{l}\text { UFRGS } \\
\text { UFRGS }\end{array}$ & 2017 & Encontros Bibli \\
\hline $\begin{array}{l}\text { Mediação da informação nas } \\
\text { discussões sobre os fluxos } \\
\text { informacionais }\end{array}$ & $\begin{array}{l}\text { BARBOZA, E. L; } \\
\text { ALMEIDA JÚNIOR, O. } \\
\text { F. }\end{array}$ & $\begin{array}{l}\text { UNESP } \\
\text { UNESP }\end{array}$ & 2017 & $\begin{array}{l}\text { Informação em } \\
\text { pauta }\end{array}$ \\
\hline $\begin{array}{l}\text { Fluxo de informação em } \\
\text { desastres naturais: os quatro } \\
\text { desafios para as ações de } \\
\text { respostas }\end{array}$ & $\begin{array}{l}\text { CARDOSO, D.; } \\
\text { PINTO, A. L. }\end{array}$ & $\begin{array}{l}\text { UFSC } \\
\text { UFSC }\end{array}$ & 2017 & $\begin{array}{l}\text { Revista Brasileira } \\
\text { de Biblioteconomia } \\
\text { e Documentação } \\
\text { (RBBD) }\end{array}$ \\
\hline $\begin{array}{l}\text { Fluxos de informação em } \\
\text { projetos de inovação: estudo } \\
\text { em três organizações }\end{array}$ & $\begin{array}{l}\text { ARAÚJO, W. C. O.; } \\
\text { SILVA, E. L.; } \\
\text { RADOS, G. J. V. }\end{array}$ & $\begin{array}{l}\text { UFSC/UFC } \\
\text { UFSC } \\
\text { UFSC }\end{array}$ & 2017 & $\begin{array}{l}\text { Perspectivas em } \\
\text { Ciência da } \\
\text { Informação }\end{array}$ \\
\hline
\end{tabular}

Perspectivas em Gestão \& Conhecimento, João Pessoa, v. 10, número especial, p. 136-159, mar. 2020. 


\begin{tabular}{|c|c|c|c|c|}
\hline $\begin{array}{l}\text { Uma proposta de taxonomia } \\
\text { para a categorização das falhas } \\
\text { no ambiente das cadeias de } \\
\text { suprimentos }\end{array}$ & $\begin{array}{l}\text { CARVAJAL, M. P.; } \\
\text { DUTRA, M. } \\
\text { MACEDO, D. }\end{array}$ & $\begin{array}{l}\text { UFSC } \\
\text { UFSC } \\
\text { UFSC }\end{array}$ & 2017 & Em questão \\
\hline $\begin{array}{l}\text { BPM Acadêmico: Mapeamento } \\
\text { de processos e de fluxos } \\
\text { informacionais na } \mathrm{ECl} / \mathrm{UFMG}\end{array}$ & $\begin{array}{l}\text { AGANETTE, E. C.; } \\
\text { MACULAN, B. C. M. } \\
\text { S.; } \\
\text { LIMA, G. A. }\end{array}$ & $\begin{array}{l}\text { UFMG } \\
\text { UFMG } \\
\text { UFMG }\end{array}$ & 2018 & $\begin{array}{l}\text { Pesquisa Brasileira } \\
\text { em Ciência da } \\
\text { Informação e } \\
\text { Biblioteconomia - } \\
\text { PBCIB }\end{array}$ \\
\hline $\begin{array}{lr}\text { Narrativa no fluxo } & \text { de } \\
\text { informação durante } & \text { o } \\
\text { compartilhamento } & \text { de } \\
\text { conhecimento em micro e } \\
\text { pequenas empresas: um } \\
\text { estudo multicaso }\end{array}$ & $\begin{array}{l}\text { SANTOS, T. C. S.; } \\
\text { TRZEACIK, D. S.; } \\
\text { RADOS, G. J. V. }\end{array}$ & $\begin{array}{l}\text { UFSC } \\
\text { UFSC } \\
\text { UFSC }\end{array}$ & 2018 & $\begin{array}{l}\text { Informação \& } \\
\text { Informação }\end{array}$ \\
\hline $\begin{array}{l}\text { A interdisciplinaridade da } \\
\text { Ciência da Informação e suas } \\
\text { contribuições no estudo do } \\
\text { compartilhamento de dados } \\
\text { governamentais na internet }\end{array}$ & $\begin{array}{l}\text { MOREIRA, F. M.; } \\
\text { VALENTIM, M. L. M.; } \\
\text { SANTA'ANA, R. C. G. }\end{array}$ & $\begin{array}{l}\text { UNESP } \\
\text { UNESP } \\
\text { UNESP }\end{array}$ & 2018 & Em questão \\
\hline $\begin{array}{l}\text { Fluxo na gestão da informação } \\
\text { técnica e científica do instituto } \\
\text { federal catarinense }\end{array}$ & $\begin{array}{l}\text { CHINI, B. R.; } \\
\text { BLATTMANN, U. }\end{array}$ & $\begin{array}{l}\text { UFSC } \\
\text { UFSC }\end{array}$ & 2018 & $\begin{array}{l}\text { Perspectivas em } \\
\text { Gestão \& } \\
\text { Conhecimento }\end{array}$ \\
\hline $\begin{array}{l}\text { A inovação nas redes sociais } \\
\text { digitais: discurso e prática em } \\
\text { empresas de } e \text {-service }\end{array}$ & $\begin{array}{l}\text { KAVA, L.; } \\
\text { BOTELHO- } \\
\text { FRANCISCO, R. E. }\end{array}$ & $\begin{array}{l}\text { UFPR } \\
\text { UFPR }\end{array}$ & 2018 & A.to.Z \\
\hline $\begin{array}{l}\text { Fluxo de Informação em } \\
\text { ambiente organizacional }\end{array}$ & SUGAHARA, C. & PUC-Campinas & 2019 & $\begin{array}{l}\text { Rev. Interam. } \\
\text { Bibliot. Medellín }\end{array}$ \\
\hline $\begin{array}{l}\text { Convergências de padrões de } \\
\text { interoperabilidade para o fluxo } \\
\text { de informações entre as redes } \\
\text { de atenção à saúde no portal } \\
\text { do DATASUS }\end{array}$ & $\begin{array}{l}\text { FREIRE, M.; } \\
\text { MEIRELLES, R. F.; } \\
\text { CUNHA, F. J. A. P. }\end{array}$ & $\begin{array}{l}\text { UFBA } \\
\text { UFBA } \\
\text { UFBA }\end{array}$ & 2019 & Ponto de Acesso \\
\hline $\begin{array}{l}\text { Fluxo de informação no } \\
\text { contexto contábil }\end{array}$ & $\begin{array}{l}\text { BARBOZA, E. L; } \\
\text { ROA, M. M. }\end{array}$ & $\begin{array}{l}\text { UNESP } \\
\text { IESF }\end{array}$ & 2019 & $\begin{array}{l}\text { Revista Ciência da } \\
\text { Inf. e } \\
\text { Documentação } \\
\text { (Incid) }\end{array}$ \\
\hline
\end{tabular}

Fonte: Dados da pesquisa (2019) 